\title{
Article \\ Structure and Dynamics of Meprin $\beta$ in Complex with a Hydroxamate-Based Inhibitor
}

\author{
Miriam Linnert ${ }^{1, *,+} \mathbb{1}$, Claudia Fritz ${ }^{1,+}{ }^{\mathbb{D}}$, Christian Jäger $^{2}$, Dagmar Schlenzig ${ }^{1}$, Daniel Ramsbeck ${ }^{1} \mathbb{1}$, \\ Martin Kleinschmidt ${ }^{1}$ (D), Michael Wermann ${ }^{1}$, Hans-Ulrich Demuth ${ }^{1,3}$, Christoph Parthier ${ }^{4}$ (D) \\ and Stephan Schilling 1,3,*
}

1 Fraunhofer Institute for Cell Therapy and Immunology, Department of Drug Design and Target Validation, Weinbergweg 22, 06120 Halle (Saale), Germany; claudia.spahn@izi.fraunhofer.de (C.F.); dagmar.schlenzig@izi.fraunhofer.de (D.S.); daniel.ramsbeck@izi.fraunhofer.de (D.R.); martin.kleinschmidt@izi.fraunhofer.de (M.K.); michael.wermann@izi.fraunhofer.de (M.W.); hans-ulrich.demuth@t-online.de (H.-U.D.)

2 Vivoryon Therapeutics N. V., Weinbergweg 22, 06120 Halle (Saale), Germany; christian.jaeger@izi-extern.fraunhofer.de

3 Faculty of Applied Biosciences and Process Engineering, Anhalt University of Applied Sciences, Bernburger Street 55, 06366 Köthen, Germany

4 Institute of Biochemistry and Biotechnology, Charles-Tanford-Proteinzentrum, Martin-Luther-University Halle-Wittenberg, Kurt-Mothes-Street 3a, 06120 Halle (Saale), Germany; christoph.parthier@biochemtech.uni-halle.de

check for updates

Citation: Linnert, M.; Fritz, C.; Jäger, C.; Schlenzig, D.; Ramsbeck, D.; Kleinschmidt, M.; Wermann, M.; Demuth, H.-U.; Parthier, C.; Schilling, S. Structure and Dynamics of Meprin $\beta$ in Complex with a Hydroxamate-Based Inhibitor. Int. J. Mol. Sci. 2021, 22, 5651. https:// doi.org/10.3390/ijms22115651

Academic Editor:

Tatyana Karabencheva-Christova

Received: 5 May 2021

Accepted: 21 May 2021

Published: 26 May 2021

Publisher's Note: MDPI stays neutral with regard to jurisdictional claims in published maps and institutional affiliations.

Copyright: (C) 2021 by the authors. Licensee MDPI, Basel, Switzerland. This article is an open access article distributed under the terms and conditions of the Creative Commons Attribution (CC BY) license (https:// creativecommons.org/licenses/by/ $4.0 /)$
* Correspondence: miriam.linnert@izi.fraunhofer.de (M.L.); stephan.schilling@izi.fraunhofer.de (S.S.)

+ Both authors contributed equally.

Abstract: The astacin protease Meprin $\beta$ represents an emerging target for drug development due to its potential involvement in disorders such as acute and chronic kidney injury and fibrosis. Here, we elaborate on the structural basis of inhibition by a specific Meprin $\beta$ inhibitor. Our analysis of the crystal structure suggests different binding modes of the inhibitor to the active site. This flexibility is caused, at least in part, by movement of the C-terminal region of the protease domain (CTD). The CTD movement narrows the active site cleft upon inhibitor binding. Compared with other astacin proteases, among these the highly homologous isoenzyme Meprin $\alpha$, differences in the subsites account for the unique selectivity of the inhibitor. Although the inhibitor shows substantial flexibility in orientation within the active site, the structural data as well as binding analyses, including molecular dynamics simulations, support a contribution of electrostatic interactions, presumably by arginine residues, to binding and specificity. Collectively, the results presented here and previously support an induced fit and substantial movement of the CTD upon ligand binding and, possibly, during catalysis. To the best of our knowledge, we here present the first structure of a Meprin $\beta$ holoenzyme containing a zinc ion and a specific inhibitor bound to the active site. The structural data will guide rational drug design and the discovery of highly potent Meprin inhibitors.

Keywords: Meprin B; Meprin beta; metalloproteinase; astacin; hydroxamate; SAR (structure activity relationship); MWT-S-270

\section{Introduction}

Meprins (Meprin $\alpha$ and $\beta$ ) are multidomain, Zn-dependent proteases. They belong to the astacin family and metzincin superfamily of endo-proteinases. Originally discovered in the early 1980s in human intestine and mouse kidney [1-3], Meprins have only been described in vertebrate tissue such as human skin, leukocytes and various cancer cells. They are involved in a broad range of proteolytic processes, among these connective tissue homeostasis and immunological and intestinal barrier function [4-6]. Meprins are key players in the processing of procollagen I and III and are potentially involved in pathological conditions such as fibrosis or keloids. Hence, the development of selective 
and potent inhibitors represents a vital approach for treatment of fibrosis, nephritis and neurodegeneration [7].

From a structural perspective, meprins are intermolecular disulfide-bridged homodimeric or heterodimeric complexes of the evolutionary related multidomain subunits, Meprin $\alpha$ and Meprin $\beta$ [8,9]. Meprin A (EC 3.4.24.18) is either composed of $\alpha \beta$-heterodimers, which tends to form tetramers $\left(\alpha_{2} \beta_{2}, \alpha_{3} \beta_{1}\right)$, or composed of $\alpha \alpha$-homodimers with up to 100 subunits, which form ring-, circle-, spiral- and tube-like non-covalent congregated complexes. Meprin B (EC 3.4.24.63) is only known as a homodimer of $\beta$ subunits $[10,11]$. Each $\alpha$ and $\beta$ subunit contains an $\mathrm{N}$-terminal signal peptide for translocation into the secretory pathway and a pro-peptide, which is removed from the zymogen by trypsin-like proteinases upon activation [12]. The pro-peptide is followed by an astacin-like protease domain, a MAM domain (Meprin A5 protein tyrosine phosphatase $\mu$ ), and a TRAF domain (tumor-necrosis-factor-receptor-associated factor). The MAM and TRAF domains are involved in protein-protein interactions and signal transduction [13-15]. The cysteine residues that form a dimer-connecting intermolecular disulfide bridge are located within the MAM domain. An EGF-like domain (epidermal growth factor like), a transmembrane domain and a cytosolic tail form the C-terminal region of meprins $[3,16]$. The major structural difference between Meprin $\alpha$ and $\beta$ represents an inserted domain containing a furin cleavage site, which is located N-terminal of the EGF-like domain in Meprin $\alpha$. Furin cleavage of Meprin $\alpha$ leads to the release of complexes composed only of Meprin $\alpha$ into the extracellular space, whereas Meprin $\beta$-containing complexes are still located at the cell membrane [17,18].

The first structure of the family prototypic astacin from freshwater crayfish Astacus astacus was solved by X-ray crystallography in $1992[19,20]$. The crystal structure of the multidomain Meprin $\beta$ (Meprin B) was solved 20 years later [21]. The protease domains of the enzymes show a remarkably high structural similarity. The protease domains fold into an N-terminal "upper" (NTS) and a C-terminal "lower" subdomain (CTS). Both subdomains are separated by a deep and narrow active site cleft, which harbors a catalytic zinc ion at its base. As with all proteases from the metzincin superfamily, astacins possess the conserved zinc-binding motif HExxHxxGxxH. This is followed by an astacin-characteristic glutamate residue C-terminal of the third histidine and the so-called Met-turn [22-24]. This is a five-residues-containing loop with a strictly conserved methionine at the third and a tyrosin at the fifth position. In activated astacins, the catalytic zinc ion is coordinated by the three histidins from the zinc binding motif and a water molecule. In the prototypic astacin protease from Astacus astacus, the hydroxyl group of the afore mentioned tyrosine from the Met-turn coordinates the zinc at a fifth side, whereby in other astacins, including the meprins, the coordination of the zinc ion by this tyrosine is not fully clear $[21,25]$. The substrates of the astacin proteinases bind while sprawled over the active site cleft. Binding involves at least four amino acids each on the $\mathrm{N}$-terminal non-prime $(\mathrm{P})$ and the $\mathrm{C}$-terminal prime site $\left(\mathrm{P}^{\prime}\right)$ of the scissile peptide bond [26,27]. Meprin $\beta$ shows a striking preference for negatively charged amino acids proximal to the scissile bond [28,29].

On the basis of the metalloproteinase inhibitor N-isobutyl-N-(4-methoxy- phenylsulfonyl)glycyl hydroxamic acid (NNGH) [30], we reported the development of selective and potent synthetic small molecule inhibitors of Meprin $\alpha$ and $\beta$ [31-33] by bio-isosteric replacement of the sulfonamide residue by a tertiary amine. This replacement led to an inhibition of astacin metalloproteinases, but not of other investigated members of the metzincin family. While retaining the hydroxamic acid and tertiary amine scaffold, differentially substituted inhibitors have been developed by elucidating their structure-activity relationships (SAR), resulting in a selective inhibitor of Meprin $\beta$ with two meta-substituted carboxy-benzyl side chains (MWT-S-270; 3-[[(3-Carboxyphenyl)methyl-[2-(hydroxyamino)2-oxoethyl]amino]methyl]benzoic acid). It was shown that the acidic substitution is important for the high inhibitory potency against Meprin $\beta$ over Meprin $\alpha$ or other related proteinases, e.g., MMPs and ADAMs [33]. The SAR and the accompanying in silico docking studies led to the assumption that ionic interactions between the meta-carboxylic acid groups and $\mathrm{Arg}^{184}$ in the $\mathrm{S} 1$ subsite and/or $\mathrm{Arg}^{238}$ in the $\mathrm{S}^{\prime}$ subsite might be important 
for inhibitor binding [33]. To investigate this interaction in detail, we crystallized the catalytically active ectodomain of human Meprin $\beta$ in complex with the tertiary-amine inhibitor MWT-S-270. To our knowledge, this is the first attempt to crystallize Meprin $\beta$ in complex with a specific small-molecule inhibitor.

\section{Results}

\subsection{Preparation of Meprin $\beta^{62-595}(\mathrm{M} \beta \Delta C)$ for Crystallization}

Meprin $\beta$ was produced in Pichia pastoris, applying an optimized version of a previously described protocol [34]. Compared with the previous approach, we modified the expression construct including the pro-peptide-, catalytic, MAM- and TRAF-domain. The formerly described N-His-Meprin $\beta^{23-652}$ was shortened resulting in N-His-Meprin $\beta^{23-595}(\mathrm{pM} \beta \Delta \mathrm{C})$ (Figure 1A) in order to remove flexible regions. The activation of Pro-Meprin by trypsin resulted in removal of the poly-histidin tag and the pro-peptide (Figure S1). For the purified, truncated variant Meprin $\beta^{62-595}(\mathrm{M} \beta \Delta \mathrm{C})$, despite reduced protein yield, identical specific activity was detected when compared with the previous variant Meprin $\beta^{62-562}$ (not shown).

A

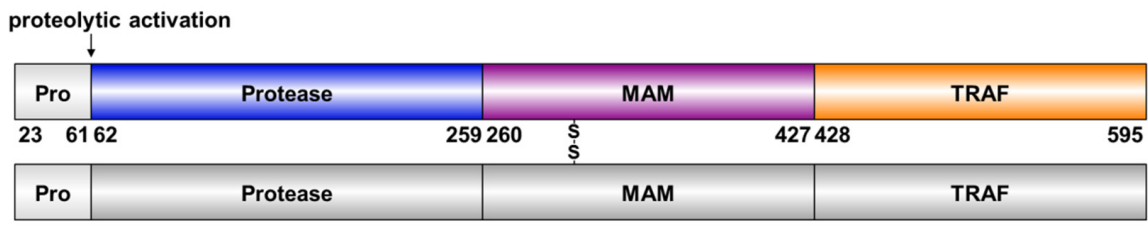

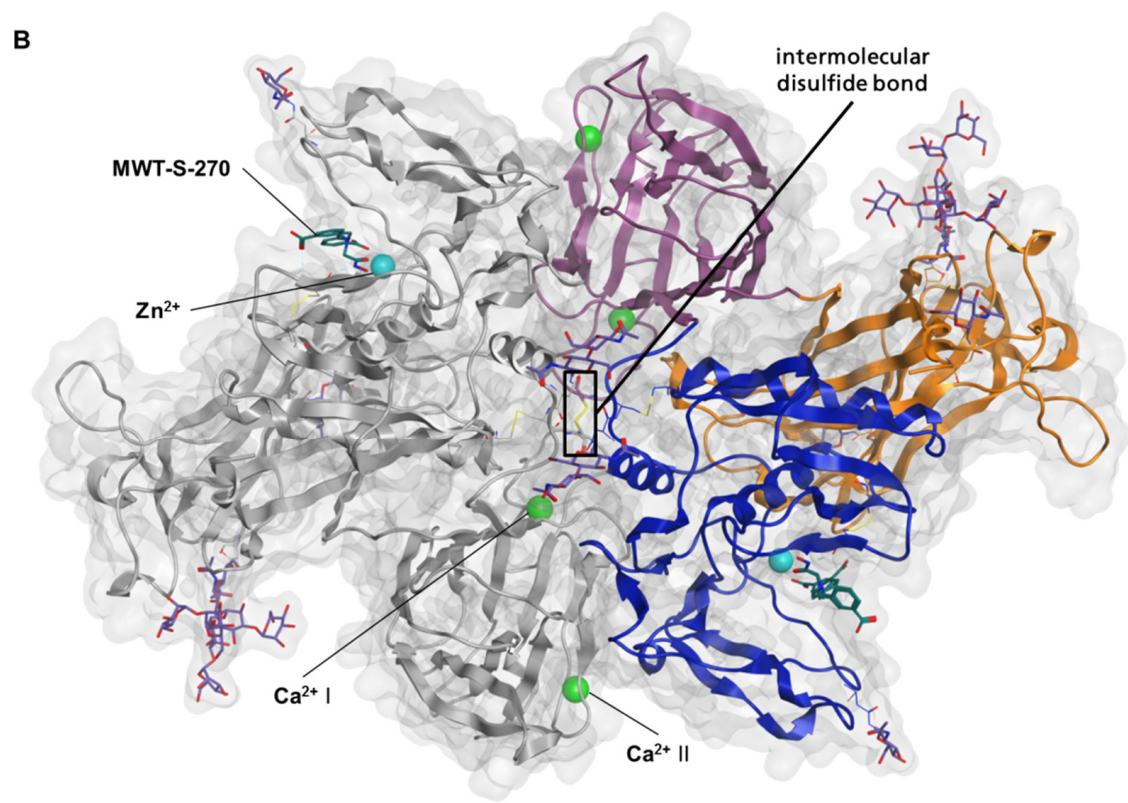

Figure 1. Structure of the Meprin $\beta$ homodimer (Meprin B). (A) Schematic representation of the human Meprin $\beta$ construct $(\mathrm{pM} \beta \Delta \mathrm{C})$ isolated from Pichia pastoris after heterologous expression. The protein includes the pro-peptide (Thr ${ }^{23}-\mathrm{Arg}^{61}$, light grey), the protease domain (Asn ${ }^{62}-$ Leu $^{259}$; blue), the MAM-domain (Ser ${ }^{260}$-Cys ${ }^{427}$; magenta) and the TRAF-domain (Pro ${ }^{428}-\mathrm{Gln}^{595}$; orange). The second monomer of the homodimer is shown in plain dark grey. After activation by trypsin the mature protein consists of amino acids $\mathrm{Asn}^{62}-\mathrm{Gln}^{595}(\mathrm{M} \beta \Delta \mathrm{C})$. Residue numbering according to Arolas et al. [21]. (B) Solved structure of the Meprin $\beta^{62-595}(\mathrm{M} \beta \Delta \mathrm{C})$ homodimer, connected by an intermolecular disulfide-bridge between Cys ${ }^{305}$ of monomer A and B. The same color code was chosen as in the schematic representation (monomer A colored, monomer B grey). Additionally, the molecular surface is shown in light grey. Protein N-glycosylation sites at asparagine side chains are represented as light blue sticks. Two calcium ions (green sphere), I and II, as well as a zinc ion (cyan sphere) and the inhibitor MWT-S-270 (dark green sticks) in the active site (protease domain) are shown in both monomers.

For reduction of potential heterogeneity, flexible glycosyl chains were removed by deglycosylation. The influence of different detergents and protein concentrations on the 
deglycosylation and stability of the enzyme has been investigated and analyzed by SDSPAGE. At high Meprin $\beta^{62-595}(\mathrm{M} \beta \Delta \mathrm{C})$ concentrations, protein precipitation was observed during the deglycosylation process. Hence, the concentration of Meprin $\beta^{62-595}(\mathrm{M} \beta \Delta \mathrm{C})$ was kept at $0.5 \mathrm{mg} / \mathrm{mL}$ for deglycosylation (Figure S2A). In the progress of protein crystallization, a stability test using the concentrated protein was performed at $15{ }^{\circ} \mathrm{C}$ for up to 15 days. In absence of an inhibitor, Meprin $\beta^{62-595}(\mathrm{M} \beta \Delta \mathrm{C})$ was degraded under these conditions (Figure S2B), obviously due to proteolytic cleavage. To prevent degradation, the non-specific Meprin $\beta$ inhibitor actinonin or the specific Meprin $\beta$ inhibitor MWT-S-270 was added to the protein solution in a molar ratio of 1:1.3 and 1:1.2, respectively. By addition of one of these inhibitors, the degradation of Meprin $\beta^{62-595}(\mathrm{M} \beta \Delta \mathrm{C})$ was prevented (Figure S2C), supporting auto-proteolytic activity at high enzyme concentration [35]. Therefore, Meprin $\beta^{62-595}(\mathrm{M} \beta \Delta \mathrm{C})$ was crystallized only in the presence of MWT-S-270.

\subsection{Structure of Meprin $\beta^{62-595}(M \beta \Delta C)$ in Complex with MWT-S-270}

The mature Meprin $\beta$ variant Meprin $\beta^{62-595}(\mathrm{M} \beta \Delta \mathrm{C})$ crystallized in the presence of MWT-S-270 in two different space groups, the already reported [21] hexagonal space group $\mathrm{P}_{1} 22$ (178) (data not shown) and, additionally, under the conditions reported here, in the monoclinic space group C2 (5), with two monomers in the asymmetric unit. Data sets from a monoclinic crystal were collected and analyzed to a resolution of $2.4 \AA$ A After phasing by molecular replacement and iterative cycles of model building and refinement, a final model with an $R_{\text {work }}=0.20$ and $R_{\text {free }}=0.24$ was achieved. Data collection and refinement statistics are given in Table 1.

Table 1. Collection and refinement statistics. (Statistics for the highest-resolution shell are shown in parentheses).

\begin{tabular}{|c|c|}
\hline & Meprin $\beta /$ MWT-S-270 \\
\hline 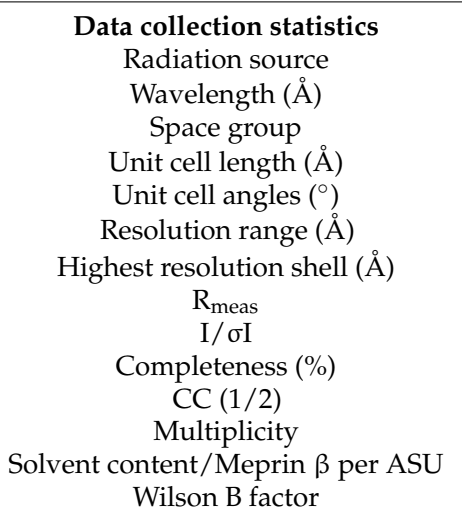 & $\begin{array}{c}\text { Rotating anode } \\
1.5418 \\
\text { C } 121 \\
162.25,72.44,135.47 \\
90,118.43,90 \\
50-2.41 \\
2.48-2.41 \\
13.1(112.9) \\
11.48(1.79) \\
99.1(95.5) \\
99.7(74.6) \\
5.6(5.1) \\
58 \% / 2 \\
41.01\end{array}$ \\
\hline $\begin{array}{l}\text { Refinement statistics } \\
\text { Number of reflections } \\
\text { (working/test set) } \\
\mathrm{R}_{\text {work }} / \mathrm{R}_{\text {free }} \\
\text { No. atoms } \\
\text { Protein } \\
\text { Ligand } \\
\text { Water } \\
\text { Average B-factors }\left(\AA^{2}\right) \\
\text { Protein } \\
\text { Ligand } \\
\text { Water } \\
\text { Bond length r.m.s.d. }(\AA) \\
\text { Bond Angles r.m.s.d. }\left({ }^{\circ}\right) \\
\text { Ramachandran plot }(\%): \\
\text { favored/allowed/outliers } \\
\text { MolProbity clashscore }\end{array}$ & $\begin{array}{c}103,499 / \\
5195 \\
0.20 / 0.24 \\
\\
8542 \\
431 \\
417 \\
52.27 \\
51.77 \\
68.94 \\
45.31 \\
0.003 \\
0.63 \\
97.8 / 1.98 / 0.19 \\
0.75\end{array}$ \\
\hline
\end{tabular}

$\overline{\mathrm{R}_{\text {meas }}}=$ redundancy independent indicator of data quality [36]. 
The final model comprises two Meprin $\beta^{62-595}$ monomers, A and B, containing the amino acids $\mathrm{Asn}^{62}-\mathrm{Thr}^{594}$. Electron density was not observed for the terminal residue Gln ${ }^{595}$. Each monomer spans the catalytic active protease domain $\left(\mathrm{Asn}^{62}-\mathrm{Leu}^{259}\right)$, the MAM-domain $\left(\mathrm{Ser}^{260}{ }_{-} \mathrm{Cys}^{427}\right.$ ) and the TRAF-domain $\left(\mathrm{Pro}^{428}{ }_{-} \mathrm{Gln}^{595}\right.$ ) (Figure 1B). Both monomers are covalently linked through an intermolecular disulfide bridge connecting residue $\mathrm{Cys}^{305}$ of monomer $\mathrm{A}$ and $\mathrm{B}$. This feature could not be observed in the crystal structure described previously [21]. Additionally, electron density was observed for four intramolecular disulfide bonds per monomer, connecting Cys ${ }^{103}-\mathrm{Cys}^{255}$, Cys ${ }^{124}-\mathrm{Cys}^{144}$, $\mathrm{Cys}^{265}$-Cys $^{273}$ and $\mathrm{Cys}^{340}-$ Cys $^{427}$.

To facilitate crystallization, the purified Meprin $\beta^{62-595}(\mathrm{M} \beta \Delta \mathrm{C})$ was deglycosylated by Endoglycosidase $\mathrm{H}$, which cleaves the 1,4- $\beta$-O-glycosidic bond between the first and the second N-acetylglucosamine residue linked to the asparagine side chain. Apparently, Asn ${ }^{218}$, $\mathrm{Asn}^{445}$ and $\mathrm{Asn}^{592}$ were deglycosylated by Endo $\mathrm{H}$ treatment, whereas $\mathrm{Asn}^{254}$ still harbors $2 \mathrm{~N}$-acetylglucosamine residues. Asn ${ }^{547}$ was not deglycosylated in both monomers under the chosen conditions. Each monomer comprises at least three bound metal ions: two tentative calcium ions and a catalytic zinc ion. One calcium (I) is octahedrally coordinated in both monomers by $\mathrm{Asp}^{418}$ (bidentate), Asp ${ }^{298}, \mathrm{Glu}^{268}$, $\mathrm{Ser}^{300}$, $\mathrm{Ser}^{266}$ and $\mathrm{Phe}^{310}$ (Figure S3A,B). The presence of calcium is supported by anomalous scattering, the characteristic metalprotein distances and the octahedral coordination geometry [37]. A second calcium cation (II) is coordinated by the protein ligands Asp ${ }^{281}$ (bidentate), $\operatorname{Ser}^{278}, \mathrm{Ala}^{283}$ and $\mathrm{Asp}^{284}$ in both monomers (Figure S3C,D).

Within the active site in each monomer, a zinc ion is coordinated by the $\mathrm{N} \varepsilon 2$ atoms of the three histidine residues His ${ }^{152}$ ( $\mathrm{His}^{92}$ in Astacin), $\mathrm{His}^{156}$ (His ${ }^{96}$ in Astacin) and His ${ }^{162}$ (His ${ }^{102}$ in Astacin) (Figure S3E,F). Zinc was identified by strong anomalous scattering at the zinc $\mathrm{K}_{\alpha}$ edge $\left(\lambda_{\text {peak }}=1.2816 \AA\right.$; measured at beamline i03, Diamond Light Source). In addition to the three histidine residues, the zinc ion is coordinated by the inhibitor MWT-S270. This compound is composed of a hydroxamic acid moiety linked by a tertiary amine (N6) to two meta-substituted benzoic acid moieties (C7-O16 and C17-O26) (Figure 2C). O1 and $\mathrm{O} 4$ of the hydroxamic acid coordinate the zinc as fourth and fifth ligand. The geometry of the coordination is trigonal bipyramidal showing $\mathrm{Zn}-\mathrm{N}$ coordination distances between 2.09 and $2.21 \AA$ and $\mathrm{Zn}-\mathrm{O}$ distances between 2.03 and $2.30 \AA$. Besides the interactions between $\mathrm{O} 1$ and $\mathrm{O} 4$ of the hydroxamic acid moiety and the zinc ion, a hydrogen bond is observed between $\mathrm{N} 2$ of the hydroxamic acid (H-bond donor) and the backbone carbonyl oxygen of $\mathrm{Cys}^{124}$. Additionally, an interaction between the hydroxamic acid $\mathrm{O} 1$ and the carboxyl side chain of $\mathrm{Glu}^{153}$ is present in both monomers (Figure 2 and Figure S4). 


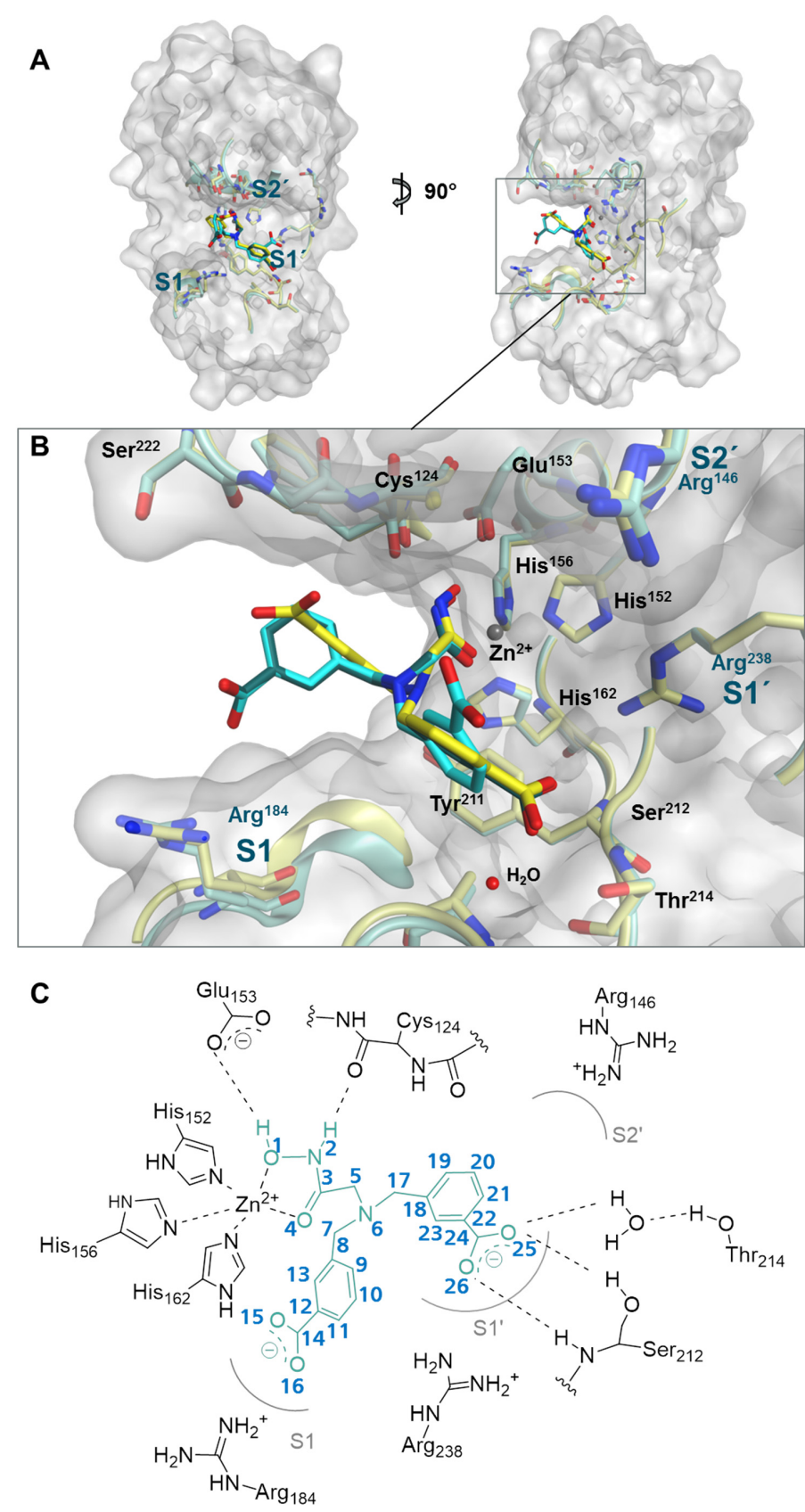

Figure 2. Interaction of MWT-S-270 with the active site of Meprin B. (A) Overlay of monomer A and monomer B of the protease domain (surface of monomer A) in "standard protease orientation" (according to Gomis-Rüth et al., 2012 [38]) (left) and rotated by $90^{\circ}$ in "side view" (right). (B) Detail view showing the ligand binding within the active site cleft. Residues from monomer A shown in light green and from monomer B in light yellow. The bound zinc ion is shown as a dark grey sphere. The inhibitor MWT-S-270 is shown in stick representation for monomer A, conformation A (dark cyan), monomer A, conformation B (light cyan) and for monomer B (yellow). The zinc ion is penta-coordinated by His ${ }^{152}$, His ${ }^{156}$ and $\mathrm{His}^{162}$ and by $\mathrm{O} 1$ and $\mathrm{O} 4$ of the hydroxamic acid moiety of MWT-S-270 (electron density is shown in Figure S4). One benzoic acid moiety is oriented towards the S1-site, the other towards the S1'-S2'site in both monomers. (C) Schematic representation (monomers A, conformation A) of MWT-S-270 bound to the active site of Meprin $\beta$. Numbering of inhibitor atoms according to the structure model indicated in blue. The inhibitor consists of a hydroxamic acid linked by a tertiary amine to two symmetric meta-benzoic acid moieties. The hydroxamic acid moiety is bidentately bound to the zinc ion within the active site. One benzoic acid moiety (C7-O16) is oriented toward the substrate-binding site S1 (containing Arg ${ }^{184}$ ). The other benzoic acid moiety (C17-O26) is oriented towards the substrate-binding sites S1' $\left(\mathrm{Arg}^{238}\right)-\mathrm{S}^{\prime}\left(\mathrm{Arg}^{146}\right)$, whereby hydrogen bonds between the carboxylate of the inhibitor and Ser 212 occur. 
The observed electron density supports the presence of the co-crystallized inhibitor MWT-S-270 spanning around the prime site from S1 to the non-prime site region of the proteolytic cleft. However, the density of the inhibitor is different in both monomers, especially for the benzoic acid moieties bound to the tertiary amine (N6) directed either to the $\mathrm{S} 1$ site (atom numbering C7-O16) or to the $\mathrm{S1}^{\prime}$ /S2' site (atom numbering C17-O26).

In monomer A, the electron density for the benzoic acid moiety (C7-O16) directed to the $\mathrm{S} 1$ subsite is not well defined. Density is observed for C7, C8, C9, C10 of the aromatic ring, but not visible for $\mathrm{C} 11, \mathrm{C} 12$ and $\mathrm{C} 13$ of the aromatic ring. From the Omit-map, calculated in the absence of MWT-S-270 (Figure S4), the same result was obtained. Enzymeinhibitor interactions of this benzoic acid moiety could not be identified within this chain. In monomer $\mathrm{B}$, the same benzoic acid moiety is oriented towards the $\mathrm{S} 1$ pocket. Here too, the electron density is not well defined. The inhibitor conformations in chain A and B differ in terms of orientation of the tertiary amine and rotation around the free rotatable C7-C8 single bond. The discussed benzoic acid moiety (C7-O16) is oriented in chains A and B towards the substrate binding pocket $\mathrm{S} 1$ of the protease, which is lined by the basic amino acid Arg ${ }^{184}$, albeit the carboxy group of this benzoic acid moiety in chain B is oriented rather towards $\mathrm{Cys}^{124}$ than to $\mathrm{Arg}^{184}$. The distance between $\mathrm{O} 16$ of the benzoic acid moiety of MWT-S-270 in chain A and the guanidino group of $\mathrm{Arg}^{184}$ is approximately $4 \AA$. In chain $\mathrm{B}$, electron density for the sidechain of $\operatorname{Arg}^{184}$ is not visible.

A lack of density is also observed for the adjacent residues in S1, Ser ${ }^{182}-\mathrm{Glu}^{185}$. These residues show higher B factors in chain B than in chain A. Different crystal contacts might provide a rationale for this observation. A possible salt bridge can form between Arg ${ }^{184}$ (chain A) and $\mathrm{Asp}^{368}$ (chain B; symmetry operation: - X,Y,-Z). In monomer B, no such interactions could be observed. The lack of clear electron density for the inhibitor and the amino acid side chains in chain B can be interpreted as significant flexibility in this region.

The other benzoic acid moiety of the inhibitor (atom numbering C17-O26) is oriented towards the substrate binding sites S1' and S2', which are lined by $\mathrm{Arg}^{238}$ and $\mathrm{Arg}^{146}$. In chain A, ambiguous density was observed at the aromatic ring of the benzoic acid. The density can be interpreted by two different inhibitor conformations, which differ by rotation around the single bond between C17 and C18. In this model, the inhibitor appears in chain $\mathrm{A}$ in two different conformations, $\mathrm{A}$ and $\mathrm{B}$. To obtain more information concerning the alternative conformations, omit map calculations in absence of single inhibitor conformers were performed (Figure S5). This analysis confirms the two different conformations of the inhibitor, each being occupied by $\sim 50 \%$. In chain $\mathrm{B}$, only one conformation was built, corresponding to the conformation $\mathrm{A}$ in chain $\mathrm{A}$. In this conformation, the inhibitor carboxylate $\mathrm{O} 26$ (O25 in chain $\mathrm{B}$ ) exhibits a hydrogen bond to the peptide backbone ( $\mathrm{N}$ of $\mathrm{Ser}^{212}$ ) and $\mathrm{O} 25$ (O26 in chain $\mathrm{B}$ ) to the $\mathrm{O} \gamma$ of $\mathrm{Ser}^{212}$ and a water molecule (not incorporated in chain B), which is further linked to $\mathrm{O} \gamma$ of $\mathrm{Thr}^{214}$ (Figure S6). The moiety of the inhibitor is oriented towards $\mathrm{Arg}^{238}\left(\mathrm{S1}^{\prime}\right)$ with an approximate distance of $4 \AA$ between O26 (O25 in chain $\mathrm{B}$ ) of the inhibitor and the guanidine group of $\mathrm{Arg}^{238}$. In addition to the different orientations of the benzoic acid moieties in monomer $\mathrm{A}$ and $\mathrm{B}$, other contacts of the inhibitor appear slightly different. In monomer A, the hydroxylic group of Tyr ${ }^{211}$ from the Met-turn is in proximity (2.9 $\AA$ ) to $\mathrm{C} 7$ of the inhibitor. In Monomer $\mathrm{B}$, the same hydroxylic group is in proximity ( $3.4 \AA$ ) to $\mathrm{C} 17$ of the inhibitor, conformation A. Furthermore, the inhibitor density in general is slightly different between both chains. In chain $A$, the density of the inhibitor seems well defined and supports both inhibitor conformations. In chain B the density seems less well defined, especially surrounding the hydroxamic acid, C5 and the tertiary amine (Figure S4).

Due to the presence of alternative binding conformations of MWT-S-270 and a high flexibility at the lower rim of the active site cleft, whether structural changes within the protease domain occur upon pro-peptide-/inhibitor-binding or maturation of the protease (Figure 3) has been investigated. A smaller distance between the upper rim and the lower rim of the active site of mature Meprin $\beta$ (pdb:4gwn), compared with the pro-form (pdb:4gwm) are in accordance with such an assumption. 
A

NTS

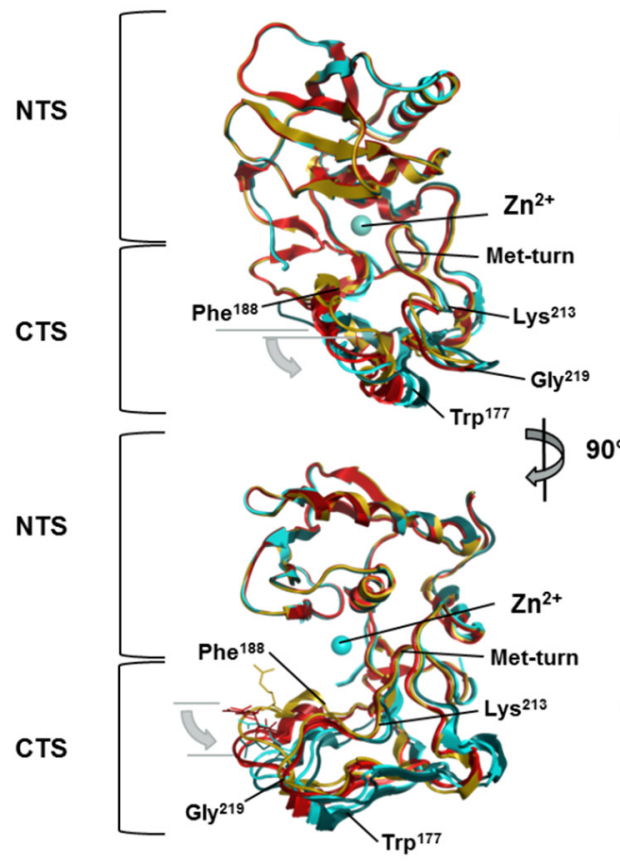

Superposition of

\author{
NTS \& CTS
}
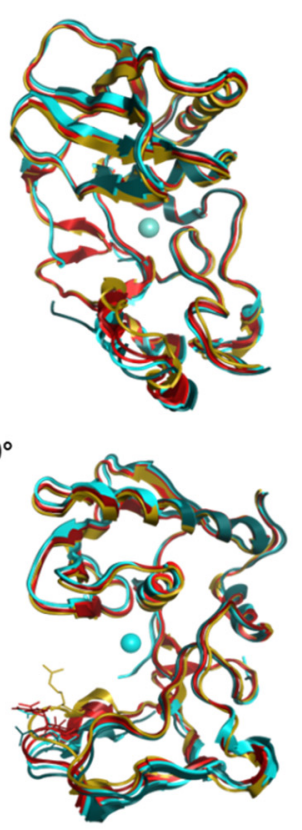

CTS
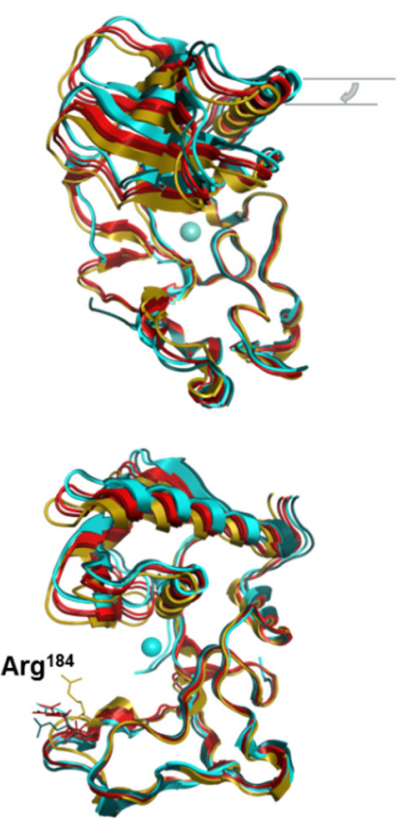

B
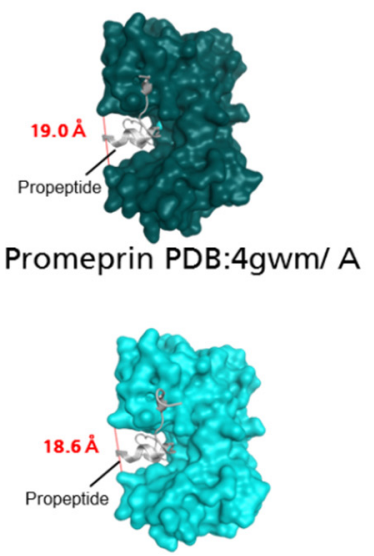

Promeprin PDB:4gwm/ B

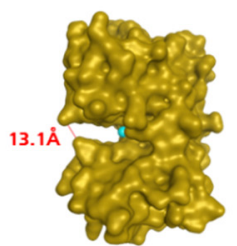

mature Meprin PDB:4gwn
C

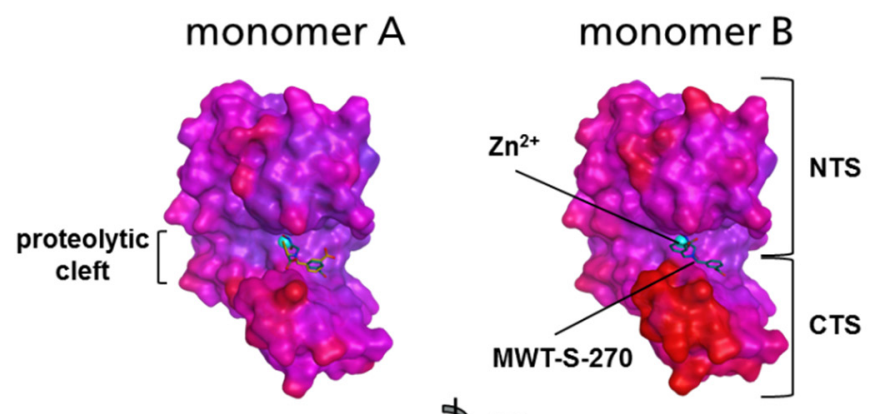

$90^{\circ}$

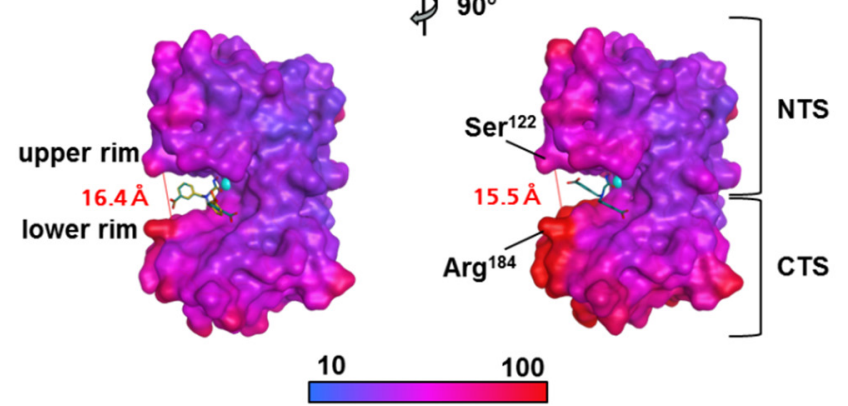

Figure 3. Structural differences of crystallized protease domains of Meprin $\beta$. Protease domain of Meprin $\beta$ in "standard protease orientation" (upper images) and after rotation in the "side view" (lower images). (A) Superposition of the protease domains from Promeprin $\beta$ (PDB:4GWM, pro-peptides are not indicated) monomer A (dark cyan) and monomer B (light cyan), mature Meprin $\beta$ (PDB:4GWN, gold), MWT-S-270-bound monomer A (light red) and monomer B (dark red). Superposed are N-terminal subdomains (NTS, left), the whole protease domain (NTS \& CTS, middle) or the C-terminal subdomains (CTS, right). (B) Molecular surface of the protease domains (side view) of Promeprin $\beta$ (PDB:4GWM) monomer A (dark cyan) and monomer B (light cyan), mature Meprin $\beta$ (PDB:4GWN, gold). Pro-peptides indicated as ribbon. (C) For both monomers (A and B) of inhibitor-bound Meprin $\beta^{62-595}(\mathrm{M} \beta \Delta \mathrm{C})$ the molecular surface is shown, colored by B factor. 
The protease domain of Meprin $\beta$ in complex with MWT-S-270 shows the same secondary structural organization as mature Meprin $\beta$ (pdb:4gwn), its pro-form (pdb:4gwm) and the prototypic astacin from Astacus astacus. The protease domain is divided by the active site cleft into an N-terminal subdomain (NTS) and a C-terminal subdomain (CTS). The N-terminal "upper" subdomain consists of a highly twisted five-stranded $\beta$-sheet flanked by two long $\alpha$-helices on its concave site. The second helix (active site helix; Ile ${ }^{147}$ Leu $\left.{ }^{158}\right)$ contains the N-terminal part of the zinc binding motif $\left(\mathbf{H}^{152} \mathrm{EFLH}^{156} \mathrm{ALGFWH}{ }^{162} \mathrm{E}\right)$ and ends at the conserved glycin $\left(\mathrm{Gly}^{159}\right)$ with a sharp turn of the polypeptide. This turn allows the chain to enter the "lower" CTS, which is characterized by short $3_{10}$-helices and 3 -turns [39]. The inhibitor-bound Meprin $\beta$ (monomer A red, monomer B dark red) was compared with both monomer structures of Promeprin $\beta$ (monomer A dark cyan, monomer $B$ cyan) and the structure of mature unbound Meprin $\beta$ (PDB:4GWN, gold) (Figure 3A).

Three different superpositions of the protease domains from both inhibitor-bound monomers (A and B), both monomers of the Pro-Meprin $\beta$ (A and B, blocked by the pro-peptide), and mature Meprin $\beta$ (native active site without inhibitor) were prepared.

In the first superposition, the whole protease domain $\left(\mathrm{Asn}^{62}-\mathrm{Leu}^{259}\right)$ was used. In the second and third, only the NST (N-terminal subdomain, Asn ${ }^{62}-\mathrm{Phe}^{160}$ ) or the CTS (Cterminal subdomain, $\operatorname{Trp}^{161}$-Leu $\left.^{259}\right)$ were considered, respectively. By superposition of the whole protease domain $\left(\mathrm{Asn}^{62}{ }^{2} \mathrm{Leu}^{259}\right)$ in the NTS $\left(\mathrm{Asn}^{62}\right.$-Phe $\left.^{160}\right)$ as well in the CTS (Trp ${ }^{161}$ $\mathrm{Leu}^{259}$ ) divergences between the different protein variants were observed. In the second superposition of the NTS, the first five amino acids of the protease domain were excluded: only Glu ${ }^{67}-\mathrm{Phe}^{160}$ were used for the superposition and the relative orientation of the NTS to CTS was kept. This analysis did not reveal any differences (RMSD $0.25 \AA$ ) in the NTS. In contrast, positional flexibility was observed within the CTS, as supported by the RMSD of $1.95 \AA$. A minor change was observed in this analysis concerning the three-turn spanning Lys $^{213}$-Gly ${ }^{219}$, C-terminal of Met-turn $\left(\mathrm{S}^{207}-\mathrm{Y}^{211}\right)$. In the middle part, an RMSD (C $\alpha$ atoms) of $1.9 \AA$ was observed between all five investigated structures. A more drastic change was seen in the region spanning two short CTS-characteristic $3_{10}$-helices, Trp ${ }^{177}$-Arg ${ }^{179}$ and $\mathrm{Glu}^{185}-\mathrm{Phe}^{188}$, and especially the intermediate three-turn spanning Leu ${ }^{181}$-Gly ${ }^{183}$. In this three-turn, the positions differ clearly as suggested by an overall RMSD (C $\alpha$ atoms) of $3.8 \AA$. This part displays the most significant differences between the monomers in the structure presented here and those published previously. In Promeprin $\beta$, Arg ${ }^{184}$ interacts with $\mathrm{Glu}^{42}$ of the pro-peptide, but in the inhibitor-bound Meprin $\beta$ as well as mature unbound Meprin $\beta$ no substituting interaction could be observed. In the inhibitorbound Meprin $\beta, \operatorname{Tr}^{177}$-Phe ${ }^{188}$ seems to be shifted, as seen for Lys ${ }^{213}-\mathrm{Gly}^{219}$, towards the position found in Promeprin $\beta$. The strongly shifted $\operatorname{Arg}^{184}$, which juts directly into the active site cleft in mature unbound Meprin $\beta$ (shown as golden sticks), is shifted more than $5 \AA$ out of the active site. This leads to an increased opening of the cleft containing the active site and of the corresponding position in the inhibitor- and in the pro-peptidebound form. By superposition of the CTS, the NTS is shifted with an RMSD of $1.96 \AA$, but again differences in the three-turn from the CTS, harboring Arg ${ }^{184}$, were observed. In summary, the superpositions led to the conclusion that both subdomains, NTS and CTS, have a distinctly different relative orientation to each other dependent on the binding state (non-/inhibitor-/pro-peptide-bound). Thus, the connection between both subdomains (Phe ${ }^{160}$-Trp ${ }^{161}$ ) appears to act as a hinge region (hinge motion). High flexibility (B-Factors) was observed especially for the three-turn, spanning Lys ${ }^{213}-G_{1 y}{ }^{219}$, and $\operatorname{Trp}^{177}-$ Phe $^{188}$ close to the lower rim of the catalytic cleft (Figure 3C).

\subsection{Interaction Analysis of Meprin $\beta^{62-595}(M \beta \Delta C)$ and MWT-S-270 by Calorimetry and Molecular Dynamics (MD)-Simulations}

Previous studies of the SAR of hydroxamate-based inhibitors aimed at targeting of arginine residues present in the active site cleft of Meprin $\beta$. Indeed, the carboxy-substituted benzoic rings in MWT-S-270 mediate a more than 100-fold stronger inhibition in comparison to Meprin $\alpha$ [33]. Because the results of the complex structure could not be interpreted 
in terms of presence of multiple salt bridges, we employed ITC to study the dependence of the dissociation constants on the ionic strength of the solvent and, thus, if any electrostatic contributions can be observed with regard to inhibitory binding. In particular, we intended to study a contribution of the benzoic acid moiety (atoms C7-O16) to the binding at the S1 subsite $\left(\mathrm{Arg}^{184}\right)$. Differently substituted inhibitors were selected for the interaction analysis (Table 2, Figure S7). All inhibitors exhibit the hydroxamic acid group bound by the Meprin $\beta$ monomers, the tertiary amine, as well one benzoic acid moiety. The other benzoic acid of MWT-S-270 was exchanged by a non-charged dioxolane moiety (2) or a non-polar, noncharged phenyl moiety (3). Legible from the ITC binding curves, in all assessments inhibitor binding occurred with one inhibitor molecule bound to one protein molecule. Binding affinities drop from $16 \mathrm{nM}\left(\Delta \mathrm{H}=-3884 \mathrm{cal} / \mathrm{mol} ;-\Delta \mathrm{S}^{*} \mathrm{~T}=-6939 \mathrm{cal} / \mathrm{mol}\right)$ for MWT-S-270 to $237 \mathrm{nM}(\Delta \mathrm{H}=-3966 \mathrm{cal} / \mathrm{mol} ;-\Delta \mathrm{S} * \mathrm{~T}=-5212 \mathrm{cal} / \mathrm{mol})$ for the non-charged dioxolane substituted variant and further to $746 \mathrm{nM}(\Delta \mathrm{H}=-1138 \mathrm{cal} / \mathrm{mol} ;-\Delta \mathrm{S} * \mathrm{~T}=-7363 \mathrm{cal} / \mathrm{mol})$ for the non-polar, non-charged phenyl substituted variant. An increase of the salt concentration from $0 \mathrm{mM}$ to $150 \mathrm{mM}$ increased the dissociation constant from $16 \mathrm{nM}$ to $400 \mathrm{nM}$ $(\Delta \mathrm{H}=-4554 \mathrm{cal} / \mathrm{mol} ;-\Delta \mathrm{S} * \mathrm{~T}=-4303 \mathrm{cal} / \mathrm{mol})$ supporting electrostatic interaction(s) as a contributor to binding of MWT-S-270 [40].

Table 2. Enzyme inhibition and thermodynamic profiling of Meprin $\beta$ inhibitors. (ITC binding curves for the titration of Meprin $\beta^{62-595}(\mathrm{M} \beta \Delta \mathrm{C})$ with the inhibitors is given in supplementary Figure $\left.\mathrm{S} 7\right)$.

ITC Buffer
[nM]

In order to study potential interaction patterns between the inhibitor MWT-S-270 and Meprin $\beta^{62-595}(\mathrm{M} \beta \Delta \mathrm{C})$ in more detail, we employed molecular dynamics simulations. The main focus was set to the fluctuating distances between the benzoic acids of MWT-S-270 and the corresponding binding partners forming the $\mathrm{S} 1$ and $\mathrm{S}^{\prime}$ sub-pockets. Therefore multiple, independent simulations (identical parameter) were performed and the resulting trajectories with mutable simulation times (between 120 nano seconds [ns] and $500 \mathrm{~ns}$ ) were analyzed. From these and other calculations (not shown) we conclude a high flexibility of the residues, shaping the lower rim (CTS) of the S1 pocket (with $\operatorname{Arg}^{184}$ as central residue), numerically calculated by RMSF-values between $1.4 \AA$ and $2.27 \AA$ (Figure S8). The framewise calculation of distances between the carboxylic oxygens (O15 \& O16) from MWT-S-270 and the guanidine nitrogens from $\operatorname{Arg}^{184}$ show, that beside the fluctuation of the $\mathrm{Arg}^{184}$ 
sidechain, an additional rotation of the benzoic acid (moiety C7-O16) occurs, providing the cause for the increasing and decreasing distances over time (Figure 4A).

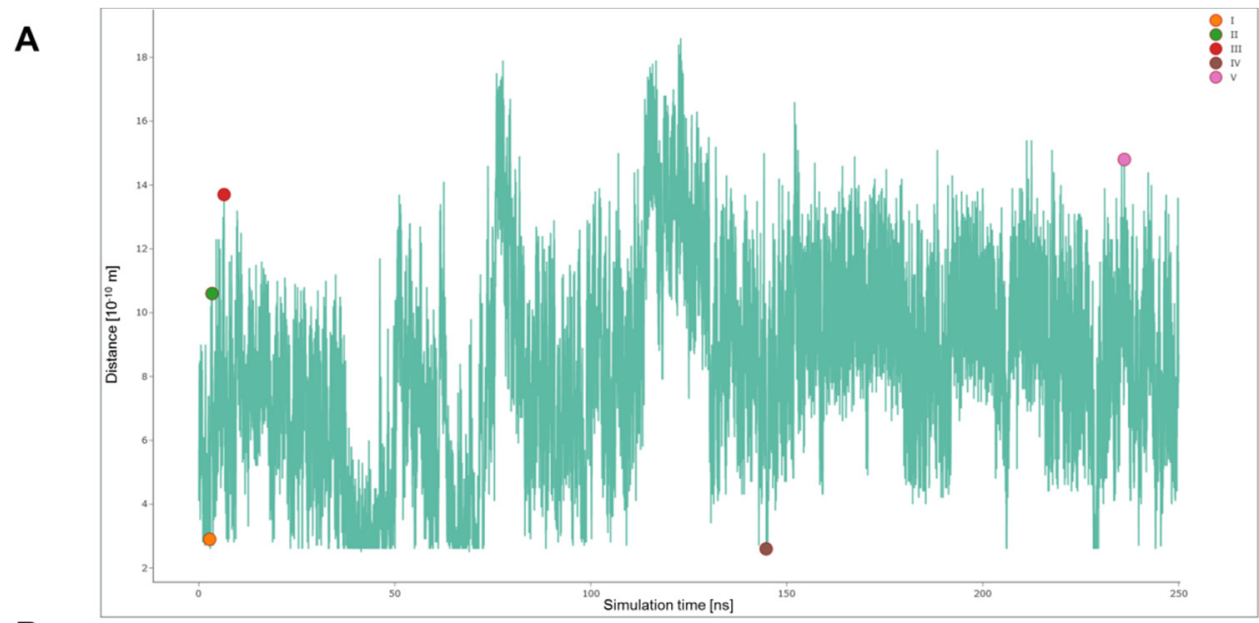

B
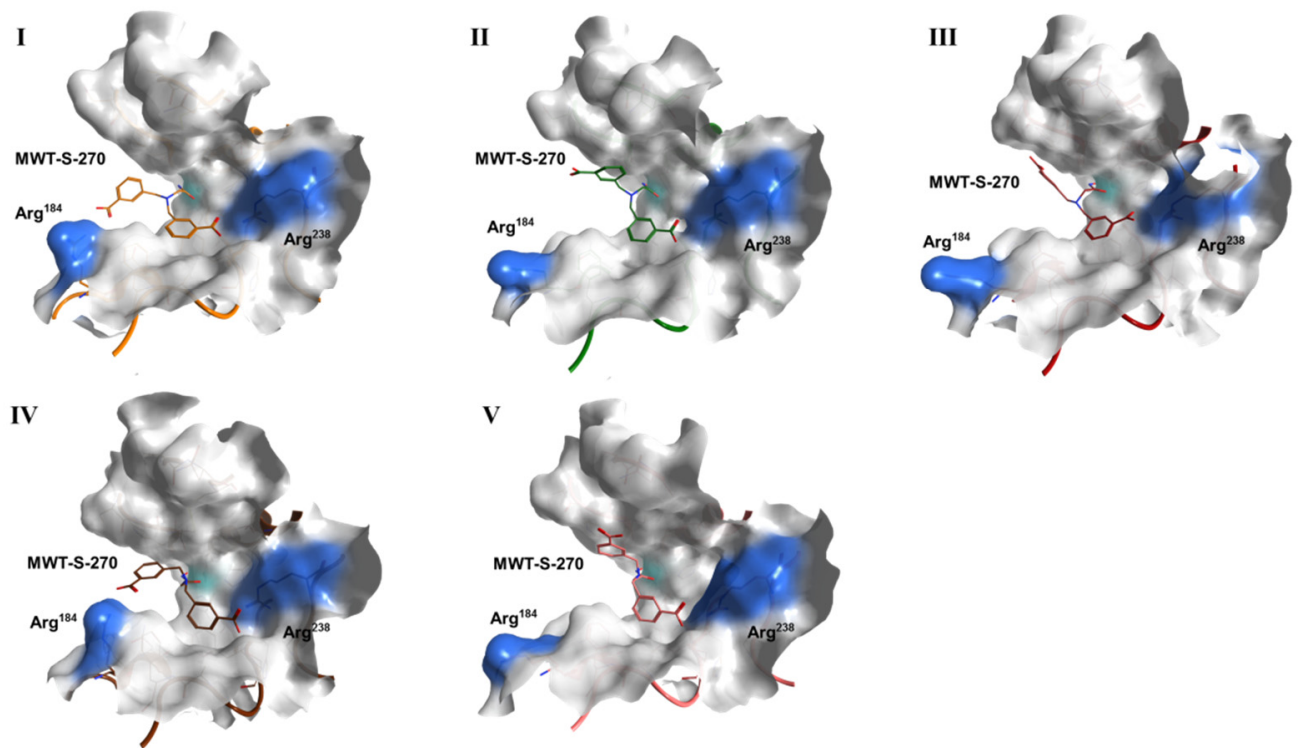

Figure 4. Molecular dynamic (MD) simulations to analyze possible interaction patterns between the inhibitor MWT-S-270 and Meprin $\beta^{62-595}(\mathrm{M} \beta \Delta \mathrm{C})$. (A) Distance Plot between guanidine Ns of Arg ${ }^{184}$ and O15/O16 of MWT-S-270 over the 250-ns MD. (B) Five conformations, which were extracted from the MD simulation (refer to the colored markers in (A)).

In addition, five snapshots were extracted from the trajectory (marked as colored circles I-V) and separately visualized in Figure 4B, and also as overlay in Figure 5. The direct comparison of the co-crystallized inhibitor with MD-snapshots poses structure II as most similar to the Inhibitor (C7-O16, both conformers), resolved in monomer A (pairwise RMSD of $1.7 \AA$ ). Structure V from Figure 4B is very close to the conformation of the inhibitor in monomer B (pairwise RMSD of $1.9 \AA$ ). An analysis of the distances of the second benzoic acid (atoms C17-O26) which faces into the S1' pocket clearly shows a very stable orientation, mainly to its counterpart $\mathrm{Arg}^{238}$ and the surrounding H-Bond network, after $90 \mathrm{~ns}$ (Figure S9). The metal coordination of the hydroxamic acid remains very stable in all simulations over time. Hence, the MD simulations provide a rationale for the conformations of MWT-S-270 observed in the crystal structures. 
A

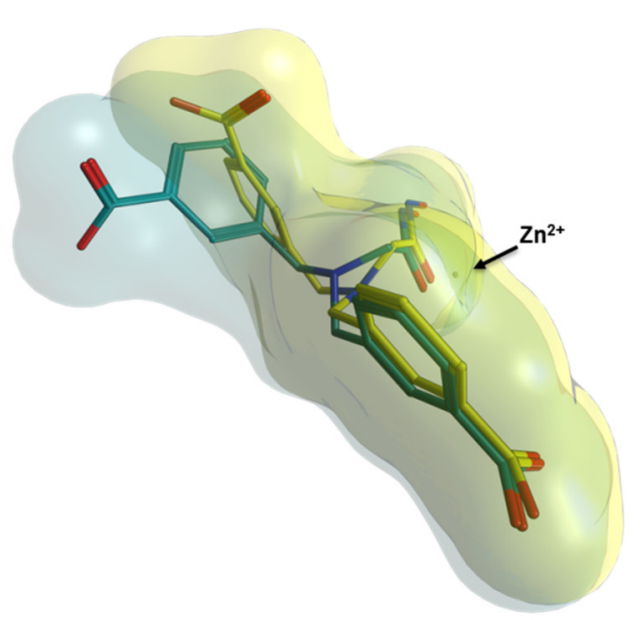

B

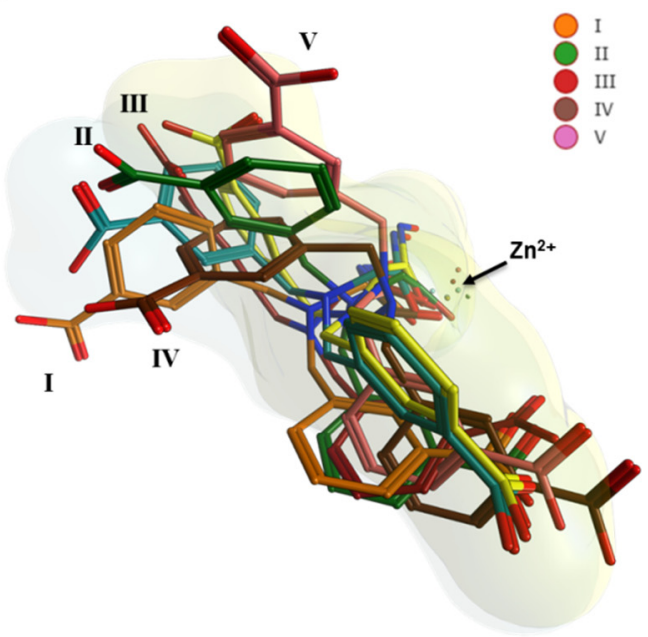

Figure 5. Overlay of experimental estimated and MD simulated MWT-S-270 within the active site of Meprin $\beta^{62-595}$ $(\mathrm{M} \beta \Delta \mathrm{C})$. (A) Overlay of co-crystallized ligand MWT-S-270 for monomer A, conformation A (dark cyan) and for monomer B (yellow). Both ligands are depicted as sticks, surrounded by its specific molecular surface, colored according to stick-color. (B) MD-snapshot-ligands I-V from Figure 4B overlayed with (A).

\section{Discussion}

A characteristic feature of astacin metalloproteinases is their remarkable preference for acidic amino acids in P1'-positon of the substrates [41]. The structural basis for this preference is a highly conserved arginine residue, shaping the bottom of the S1'-subsite of the proteinases [23]. In particular, Meprin $\beta$ exhibits a unique substrate specificity to cleave peptide substrates only composed of acidic amino acids. These cleavage characteristics are mediated by a cluster of positively charged residues within the active site cleft [21,41]. In addition to the conserved arginine $\mathrm{Arg}^{238}$ in the $\mathrm{S1}^{\prime}$-pocket, the S1- as well as the S2'-subsites of Meprin $\beta$ are formed by the arginines $\operatorname{Arg}^{184}$ and $\operatorname{Arg}^{146}$, respectively.

More recently, the first synthetic small molecule inhibitors of Meprin $\alpha$ and $\beta$ have been developed and their structure-activity relationships (SAR) have been elucidated in detail [31-33]. These studies suggested that acidic moieties are mandatory for high inhibitory potency against Meprin $\beta$ and are also a key structural feature for high selectivity over Meprin $\alpha$ or other related proteinases, e.g., MMPs and ADAMs. To obtain more detailed insight into the binding mode of these inhibitors, we co-crystallized Meprin $\beta^{62-595}(\mathrm{M} \beta \Delta \mathrm{C})$ with the selective and potent Meprin $\beta$ inhibitor MWT-S-270 and solved the structure of the complex by X-ray crystallography. The obtained structure revealed binding of the inhibitor in both monomers within the active site cleft (Figure 2). As predicted by the docking studies [31], MWT-S-270 is a "right-hand side" inhibitor addressing the S1 and S1'sites of Meprin $\beta$, thus behaving like the majority of hydroxamate-based metalloproteinase inhibitors. The hydroxamic acid moiety is bound to the zinc ion in a bidentate fashion, which is commonly observed with these inhibitors. One benzyl residue is directed to the S1-site, while the second benzyl residue of the tertiary amine is directed towards the S1'subsite, shaped by $\operatorname{Arg}^{238}$. The electron density of this residue is defined in both monomers of the dimer, suggesting interactions of the benzyl moieties within this sub-pocket. The postulated interaction of the carboxylic acid with $\mathrm{Arg}^{238}$ does not seem to generate the main commitment to binding of the inhibitor at the S1'-site, exhibiting a closest distance of 3.9 A between the oxygen of the carboxylic acid and N of the guanidinium moiety of the arginine side chain (Figure S4). In addition, in monomer A of Meprin $\beta$, we observed a second conformation of MWT-S-270 (conformer B), which is located at a distance of $6.7 \AA$ to the S2' side residue $\mathrm{Arg}^{146}$ (considering the oxygen of the carboxylic acid and $\mathrm{N}$ of the guanidinium moiety of the arginine-sidechain). 
The unexpected interaction is a fixation of the benzoic acid moiety within the S1'site via a network of hydrogen bonds, i.e., the sidechain $\mathrm{OH}$ of $\mathrm{Ser}^{212}$ at a distance of 2.8-2.9 $\AA$, the backbone $\mathrm{NH}$ of $\operatorname{Ser}^{212}$ at a distance of $3.2 \AA$ and a water-bridged hydrogen bond with $\mathrm{Thr}^{214}$ at a distance of 2.6 and $2.8 \AA$. However, this unexpected hydrogen bond network might not only be a contributor to the affinity of the inhibitor, but also to its selectivity over Meprin $\alpha$. The respective residues in Meprin $\alpha$ are $\operatorname{Gln}^{215}$ instead of $\operatorname{Ser}^{212}$ (Meprin $\beta$ ) and Phe ${ }^{217}$ instead of $\operatorname{Thr}^{214}$ (Meprin $\beta$ ) (Figure S10). Thus, the two hydrogen bond donors are replaced by bulkier residues, lacking hydrogen bond donors. This narrows the $\mathrm{S1}^{\prime}$-pocket sterically and hampers formation of the hydrogen bond network, finally leading to decreased inhibitory potency of MWT-S-270 towards Meprin $\alpha\left(\mathrm{IC}_{50}=16,050 \pm 212 \mathrm{nM}\right)[31]$.

While the same interaction of MWT-S-270 with the S1'-subsite occurs in both monomers of the dimer, the position of the benzyl residue that interacts with the S1-subsite is less defined. The closest distance between the carboxylic acid and the guanidinium moiety of $\mathrm{Arg}^{184}$ is around $4 \AA$, albeit the electron density for the C11, C12 and C13 of MWT-S-270 in monomer $\mathrm{A}$ and $\mathrm{C} 8, \mathrm{C} 9$ and $\mathrm{C} 13$ in monomer $\mathrm{B}$ is not defined, and the moiety of the inhibitor is probably highly flexible via rotation around the single bond connecting C7-C8. Moreover, the whole loop forming the lower rim of the active site cleft, harboring Arg ${ }^{184}$, is also less well resolved, as reflected by higher B-factors, especially in monomer B. The missing electron density of the side chain of $\operatorname{Arg}^{184}$ in monomer B and the barely resolved $\mathrm{Arg}^{184}$ in monomer A (together with the less well resolved whole loop) led us to conclude a high degree of flexibility. Because the crystal structure data do not allow a reliable evaluation of MWT-S-270 interactions with the S1-pocket, we performed molecular dynamics (MD) simulations. In these simulations, we see the high flexibility of the residues, shaping the lower rim (CTS) of the S1 pocket and an additional rotation of the benzoic acid of the inhibitor, with increasing and decreasing distances over time. Especially the high flexibility of the solvent-exposed residue $\mathrm{Arg}^{184}$, but also the proposed intermediate conformations of MWT-S-270, which "fills the gap" between the two states in the crystal structure model (monomer A and B), could be illustrated by MD (Figure 4). An interesting result is the direct comparison of MD-snapshot II with the inhibitor interpreted in monomer A from the X-ray structure, where the S1-subsite directed benzyl residues are close to each other but the $\mathrm{Arg}^{184}$ sidechain moves out of the cleavage site, allegedly with high solvent accessibility and associated polarization effects. The MD-snapshot IV contrasts, in that here the benzoic acid moiety is found in similar orientation as in snapshot II, but Arg ${ }^{184}$ faces the inhibitor directly with remarkably reduced distance, in comparison also with the crystal structure. Taken together, conformations II and IV support the theory of high flexibility and, therefore, weakly defined electron densities. In particular $\mathrm{Arg}^{184}$, one of the putative key residues for electrostatic interaction, exhibits high flexibility, which is even increased in the presence of the inhibitor. Thus, the flexibility of the protein in combination with the flexibility of the inhibitor might be the reason for the weakly defined electron density of the S1-site.

Nevertheless, electrostatic interactions appear crucial for the high affinity of the Meprin $\beta$ inhibitors and a directed interaction. Such a conclusion is supported by the comparison of the thermodynamics of binding of differently substituted inhibitors and the influence of ionic strength on the inhibition. Assuming a conserved interaction of the benzoic acid with the S1'-subsite, the three analyzed compounds (Table 2) differ in the residue that potentially addresses the S1-pocket. While the carboxylic acid of $\mathbf{1}$ could participate in ionic interactions and charged hydrogen bonds, the dioxolane moiety of 2 may just serve as hydrogen bond acceptor and the unsubstituted phenyl-residue of $\mathbf{3}$ does not support an electrostatic interaction with S1, e.g., $\mathrm{Arg}^{184}$. The $\mathrm{K}_{\mathrm{i}}$ values of compounds 1-3 support the formation of a directed interaction to S1 (Table 2), as concluded from the drop of the inhibition constant $\left(\mathrm{K}_{\mathrm{i}}\right)$ of $23 \mathrm{nM}$ for $\mathbf{1}$ to $1395 \mathrm{nM}$ for 3 . Thereby, the interaction of $\mathbf{1}$ is significantly driven by electrostatic interactions, which could be shown by a strong decrease of affinity in presence of $150 \mathrm{mM} \mathrm{NaCl}(16 \mathrm{nM}$ vs. $400 \mathrm{nM})$, at which the lower affinity was not caused by a weaker binding enthalpy $(\Delta \mathrm{H})(-3884 \mathrm{cal} / \mathrm{mol} \mathrm{vs}$. 
$-4554 \mathrm{cal} / \mathrm{mol})$, but the loss of favorable binding entropy $(-\Delta \mathrm{S} * \mathrm{~T})$ during the interaction $(-6939 \mathrm{cal} / \mathrm{mol}$ vs. $-4303 \mathrm{cal} / \mathrm{mol})$. In this regard, it has to be considered that the contribution of ionic forces to the binding is dependent on the environment. In an a-polar environment (e.g., interior of proteins) the formation of salt bridges is mainly driven by enthalpic contributions opposed to entropic penalties, whereas in a polar environment (e.g., surface of the protein) the ionic interactions are mainly driven by an entropic gain [42-44]. Accordingly, the favorable entropic contribution of $\mathbf{2}$ is significantly lower compared to 1. Further decreased affinity of 3 is mainly caused by the weakest binding enthalpy of all three compounds and only slightly compensated by a small entropic gain, which indicates that removal of the functional group caused the loss of directed interaction. Although the interaction partner within the S1-subsite could not be unambiguously identified by our studies due to the high flexibility, the data obtained here support the concept that interactions within the S1-subsite, e.g., $\operatorname{Arg}^{184}$ in Meprin $\beta, \operatorname{Tyr}^{187}$ in Meprin $\alpha$, Phe ${ }^{214}$ in Ovastacin and Gln ${ }^{246}$ in BMP-1, could be a key to the development of selective inhibitors for the respective proteinases.

In addition to the S1 pocket including the sidechain of $\mathrm{Arg}^{184}$ and its surrounding residues, the whole lower rim of the CTS also shows a remarkable flexibility, which is supported by high B-factors for this C-terminal subdomain, especially in Monomer B (Figure 3C). Compared with the previously reported mature Holo-Meprin $\beta$ (PDB:4GWN; [21]), the active site cleft of the inhibitor-bound Meprin $\beta$ is distinctly broadened. The distance between side chain $\mathrm{O} \gamma$ of $\operatorname{Ser}^{122}$ (outer end of the upper rim) and the guanidinium $\mathrm{N} \varepsilon$ of $\operatorname{Arg}^{184}$ (outer end of the lower rim) in the inhibitor-bound Meprin $\beta$ is $\sim 11 \AA$ (monomer A; not determined for monomer B due to lack of density for the $\operatorname{Arg}^{184}$ side chain) but in the mature Holo-Meprin $\beta$ this is only $\sim 8 \AA$. Distances of $\sim 15 \AA$ (monomer $\mathrm{A}$ and $\mathrm{B}$ ) are observed in Promeprin $\beta$ (PDB:4GWM). Such differences, although less pronounced, are also recognized for the $C \alpha$ trace. For instance, the distances of $C \alpha$ of $\operatorname{Ser}^{122}-C \alpha$ of $\operatorname{Arg}^{184}$ for inhibitor-bound Meprin $\beta$ monomer A were $16.6 \AA$, in monomer B 15,7 $\AA$, in Holo-Meprin $\beta$ 13.1 $\AA$, in Promeprin $\beta$ (PDB:4GWM) Monomer A $19 \AA$ and in Monomer B 18.6 $\AA$ (Figure 3B,C). Such alterations of the positions between NTS and CTS are observed in all Astacins, which have been analyzed so far. Only in human bone morphogenetic protein 1 (BMP1) is the active site cleft in the inhibitor-bound form (PDB:6BTN) more constricted in comparison with the non-inhibitor bound form (PDB:3EDG). Nevertheless, a movement/changed position is also observed there.

The superposition of Promeprin $\beta$, mature Meprin $\beta$ and MWT-S-270-bound Meprin $\beta$ protease domains revealed a switch in the relative orientation of the subdomains to each other, whereby the connection (Phe $\left.{ }^{160}-\operatorname{Tr}^{161}\right)$ between both subdomains may act as a hinge. For the single domain astacin from Astacus astacus, a slight hinge movement $(\sim 1 \AA)$ upon inhibitor binding has also been reported [27]. In Meprin $\beta$, the respective region (Lys ${ }^{213}$-Gly ${ }^{219}$ and Trp ${ }^{177}$-Phe ${ }^{188}$ ) within the CTS did not develop additional proteinprotein interactions upon structural change and the CTS remains solvent accessible. This contrasts with the NTS, which displays pronounced interactions with the MAM and TRAF domain as well as with the respective other monomer of the dimer. Hence, it is tempting to speculate that the CTS is the moving subdomain during binding events.

Concluding, we propose the following structural changes occurring in Meprin $\beta$ upon activation and ligand/substrate binding. Promeprin $\beta$ harbors a broader cleft of $15 \AA$ between the upper (NTS) and the lower rim (CTS) due to pro-peptide binding. Caused by pro-peptide cleavage and release, the distance between the upper and the lower rim is reduced by $\sim 7 \AA$. The newly formed active site cleft remains flexible, and may be broadened again upon inhibitor binding. Thereby, the size of the cleft depends on the structural orientation of the bound ligand, in our example this is influenced by the free rotation around the single bond connecting C7 and C8 of MWT-S-270. Depending on the type of ligand, the active site cleft maybe adjusted by hinge movement between NTS and CTS, thereby exerting an induced fit mechanism. Such a theory could be further corroborated by crystallization in complex with a more rigid ligand to fix a preferred conformation. 


\section{Materials and Methods}

\subsection{Expression and Purification of Mature Meprin $\beta^{62-595}(M \beta \Delta C)$}

Active Meprin $\beta^{62-595}(\mathrm{M} \beta \Delta \mathrm{C})$ was produced, similar to that described by Schlenzig et al. [34]. The sequence for the C-terminally truncated pro-Meprin $\beta(p M \beta \Delta C)$, spanning the amino acids 23-595 (pro-peptide-, catalytical, MAM- and TRAF-domain) was cloned into vector $\mathrm{pPICZ} \alpha \mathrm{C}$ (Cla1/Not1) downstream to sequences encoding an Nterminal His-tag and the $\alpha$-mating factor from Saccharomyces cerevisiae. The linearized expression vector was used for transformation of Pichia pastoris X33 cells. After clonal selection, cells were grown in a $5 \mathrm{~L}$ bioreactor (Biostat B, Sartorius BBI Systems $\mathrm{GmbH}$, Göttingen, Germany), according to the Pichia Fermentation Process Guidelines (Life Technologies $\mathrm{GmbH}$, Darmstadt, Germany). The heterologous expression was driven by the AOX-promoter, enabling the expression of N-His-Meprin $\beta^{23-595}$ upon feeding of methanol. The fermentation process was stopped after $72 \mathrm{~h}$ and the supernatant harvested. The recombinant Meprin was captured by chromatography on a Ni-chelating resin applying expanded bed adsorption. This was followed by cleavage of the His-tag and the pro-peptide by trypsin (bovine Trypsin, Sigma Aldrich, St. Louis, MO, USA). For removal of trypsin and denatured protein from the cleavage product (Meprin $\beta^{62-595}$ ), hydrophobic interaction chromatography (Butyl-Sepharose column, $25 \times 100 \mathrm{~mm}$; GE Healthcare, Chicago, IL, USA) was used. Finally, mature Meprin $\beta^{62-595}$ was purified by size exclusion chromatography (Superdex 75 column, $26 \times 850 \mathrm{~mm}$; GE Healthcare) and eluted in $30 \mathrm{mM}$ Tris $\mathrm{pH}$ 7.6, containing $100 \mathrm{mM} \mathrm{NaCl}$. Typically, $7 \mathrm{mg}$ of homogenous mature Meprin $\beta^{62-595}$ could be isolated from one liter of fermentation supernatant.

\subsection{Deglycosylation of Meprin $\beta^{62-595}(M \beta \Delta C)$}

For the removal of surface-exposed glycosyl chains, a deglycosylation was performed prior to crystallization. Typically, purified Meprin $\beta^{62-595}(\mathrm{M} \beta \Delta \mathrm{C})$ has been deglycosylated by Endo $\mathrm{H}\left(500 \mathrm{U} / \mathrm{mg}\right.$ Meprin $\beta$ ) at a concentration of $0.5 \mathrm{mg} / \mathrm{mL}$ at $37^{\circ} \mathrm{C}$ under non-denaturing conditions ( $50 \mathrm{mM}$ sodium acetate, $\mathrm{pH}$ 6.0) for $4 \mathrm{~h}$. Afterwards, the deglycosylated Meprin $\beta^{62-595}(\mathrm{M} \beta \Delta \mathrm{C})$ was concentrated to $19.75 \mathrm{mg} / \mathrm{mL}$ applying VivaSpin ${ }^{\circledR} 6$ (Sartorius, cut off $10 \mathrm{kDa}$ ) centrifugal concentrators. Finally, the proteolytic stability of the concentrated Meprin $\beta^{62-595}(\mathrm{M} \beta \Delta \mathrm{C})$ was tested for up to 15 days at $15^{\circ} \mathrm{C}$ in a $30 \mathrm{mM}$ Tris pH 7.6, $100 \mathrm{mM} \mathrm{NaCl}$-buffer with and without inhibitor (unspecific inhibitor: actinonin; specific: MWT-S-270) and the sample analyzed by SDS-PAGE.

\subsection{Determination of Meprin $\beta$ Activity}

The enzymatic activity of Meprin $\beta$ was determined, essentially as described previously $[34,45]$. The assay is based on the change of fluorescence intensity due to cleavage of the internally quenched peptide substrate Abz-YVAEAPK(Dnp)G-OH $\left(\lambda_{\text {ex }} 340 \mathrm{~nm} / \lambda_{\mathrm{em}}\right.$ $420 \mathrm{~nm}$ ). For activity determination during expression and purification, the proenzyme was activated by trypsin. For activation, $100 \mu \mathrm{L}$ of cleavage buffer $(50 \mathrm{mM}$ Tris $/ \mathrm{HCl}, 10 \mathrm{mM}$ $\mathrm{CaCl}_{2}, \mathrm{pH} 7.5$ ), $50 \mu \mathrm{L}$ Meprin $\beta$ solution and $50 \mu \mathrm{L}$ bovine trypsin $500 \mu \mathrm{g} / \mathrm{mL}$ (Sigma Aldrich) were mixed and incubated for $15 \mathrm{~min}$ at $30^{\circ} \mathrm{C}$. An aliquot of the reaction $(50 \mu \mathrm{L})$ was mixed again with $150 \mu \mathrm{L}$ assay buffer consisting of $40 \mathrm{mM}$ Tris $/ \mathrm{HCl}, \mathrm{pH} 8.0,0.05 \%$ Brij 30. The reaction was initiated by addition of $50 \mu \mathrm{L}$ of substrate (final concentration $50 \mu \mathrm{M})$, which was dissolved in assay buffer.

\subsection{Crystallization of Meprin $\beta^{62-595}(M \beta \Delta C)$, Data Collection and Structure Elucidation}

The inhibitor MWT-S-270, which was applied for co-crystallization, was synthesized as described by Ramsbeck et al. [31]. For crystallization trials, the purified and deglycosylated Meprin $\beta^{62-595}(\mathrm{M} \beta \Delta \mathrm{C})$ was combined with the inhibitor MWT-S-270 at a molar ratio of 1:1.2 and a final protein concentration of $8 \mathrm{mg} / \mathrm{mL}$ in $30 \mathrm{mM}$ Tris, $100 \mathrm{mM}$ sodium chloride, $\mathrm{pH}$ 7.6. Crystals were grown at $13{ }^{\circ} \mathrm{C}$ using the sitting drop vapor diffusion technique by mixing $200 \mathrm{~nL}$ of protein solution with $200 \mathrm{~nL}$ of reservoir buffer. This solution was equilibrated against $55 \mu \mathrm{L}$ of reservoir buffer containing 25\% (w/v) PEG 4000 and 30\% $(v / v)$ 
ethylene glycol in the reservoir. Crystals were harvested after 39 days. Prior to X-ray analysis, crystals were flash frozen at $-180^{\circ} \mathrm{C}$ in an X-Stream 2000 cryo stream (Rigaku/MSC) without further cryoprotection. Diffraction images of a Meprin $\beta$ single crystal were collected in-house using $\mathrm{Cu} \mathrm{K} \alpha$ radiation $(\lambda=1.5418 \AA$ ) provided by a copper rotating-anode source (RA Micromax 007, Rigaku Europe) using a CCD detector (SATURN 944+, Rigaku Europe). Oscillation images were integrated, merged, and scaled using XDS to a resolution of $2.41 \AA$ [46] according to an I/Sigma(I) of 1.8 in the highest resolution shell (Table 1). The phases were determined by molecular replacement with the program PHASER [47] using the protein data bank (PDB; https:/ / www.wwpdb.org/ (accessed on 5 May 2021)) entry 4GWN (human mature Meprin $\beta$, hexagonal crystal form) as search model. The monoclinic crystal contained two monomers in the asymmetric unit (space group C2). Initial automated model building and refinement were performed using the program AUTOBUILD from the PHENIX suite [48]. Further iterative cycles of manual model building and maximum-likelihood structure refinement were conducted using the programs COOT from the CCP4 suite [49] and PHENIX.REFINE including Non-Crystallographic Symmetry (NCS) and finally also Translation Libration Screw-motion (TLS) restraints. Non-standard ligand restraints for the inhibitor MWT-S-270 were generated with ELBOW (PHENIX suite). Bond lengths of MWT-S-270 were additionally restrained using data contained in the Cambridge Structural Database (CSD). The final model comprises the residues 62-594 for both monomers. In both chains, the inhibitor was built, based on the observed electron density. In protein monomer A, an ambiguous electron density could be a result of two alternative conformations, consequently both conformations were built and refined against occupancies. Remaining oligosaccharide residues were built manually into the electron density in accordance with the known glycosylation pattern of the expression host system Pichia pastoris [50,51]. The whole protein model was validated by MolProbity included in the PHENIX suite. Metal ions were validated using the dedicated Metal Binding Site Validation Server (CMM; http:/ / csgid.org/csgid/metal_sites (accessed on 5 May 2021)) [52]. Finally, glycosyl chains were checked using the program Privateer $[49,53]$ and interfaces were analyzed using PISA [54] of the CCP4 suite. Structure coordinates und reflection data were deposited in the PDB under accession code 7AQ1. The inhibitor MWT-S-270 was also deposited as chemical compound in the PBD under 3-letter-code RUE (CC ID). Figures were prepared using Molecular Operating Environment (MOE) v.2019.0102 (Chemical Computing Group ULC).

\subsection{Isothermal Titration Calorimetry (ITC)}

The binding affinity $\left(\mathrm{K}_{\mathrm{D}}\right)$, binding enthalpy $(\Delta \mathrm{H})$, binding entropy $(\Delta \mathrm{S})$ and stoichiometry $(\mathrm{N})$ of different Meprin $\beta$ inhibitors to Meprin $\beta^{62-595}(\mathrm{M} \beta \Delta \mathrm{C})$ were determined by isothermal titration of the inhibitors to the enzyme at $30^{\circ} \mathrm{C}$ using a VP-ITC microcalorimeter (MicroCal). Prior to the binding analysis, the purified Meprin $\beta^{62-595}(\mathrm{M} \beta \Delta \mathrm{C})$ was dialyzed extensively against $40 \mathrm{mM}$ Tris $\mathrm{pH} 8.0( \pm 150 \mathrm{mM} \mathrm{NaCl})$. The inhibitors were diluted 1:50 from DMSO stock solutions into dialysis buffer and 2\% $(v / v)$ DMSO were added to the dialyzed enzyme solution immediately before starting the titration experiment. The instrument was operated according to the manufacturer's instructions and the data analyzed using MicroCal ORIGIN software. The obtained binding heat was corrected by the dilution heat of the ligand, which was recorded by titration of the inhibitor (1:50 diluted) into the dialysis buffer containing $2 \%(v / v)$ DMSO. The corrected data were evaluated by a single-site binding model calculating $\mathrm{N}, \mathrm{K}_{\mathrm{D}}, \Delta \mathrm{H}$ and $\Delta \mathrm{S}$.

\subsection{Molecular Dynamic (MD) Simulations}

Monomer A of PDB entry 7AQ1 was used for MD simulations. All sugar and water molecules were removed and only protein residues, ions (including active site $\mathrm{Zn}^{2+}$ ) and the ligand MWT-S-270 were kept. The system was protonated at $\mathrm{pH} 7.0$ using Protonate 3D [55]. The parameter and library files of the small molecule ligand were generated by the antechamber and parmchk tools, using the Am1-BCC charge model for atomic point 
charges in combination with gaff atom types. The amber14 force field [56] was employed for the protein and ions. The ligand, protein and ions were merged into a new file and the resulting complex was inserted into a TIP4PEW [57] water box. Furthermore, the system was neutralized by adding counter ions and disulfide bridges were defined manually. It is well known that the non-bonded simulation of explicit water and ligand molecules, bound to catalytic metal ions, is challenging due to the underestimation of the interactions between water and metal [58]. Therefore, some adoptions were performed to utilize an extended lennard-jones-C4 Potential [59] as non-bonded model with fine-tuned m12-6-4 parameter set [60]. All calculations were executed on two Nvidia GeForce RTX 2080 Ti GPUs, which are part of an Intel Core I9 $(14 \times 3.3 \mathrm{GHz})$ high performance workstation $(\mathrm{HPW})$ with 128 GB RAM, running Ubuntu 18.04. All trajectories were processed using cpptraj [61] and subsequently analyzed with VMD [62-64] and RStudio-Server (V1.3.959 [65]; R V3.6.3 [66]), utilizing Bio3D [67-69] and Plotly [70].

\section{Conclusions}

In this work we present the first structure of Meprin $\beta$ in complex with a small molecule inhibitor. The data support an unexpected flexibility of the compound MWT-S270 within the active site and provide evidence for a general flexibility of the active site region. The results will have implications for the development of novel Meprin inhibitors, as already demonstrated [71]. However, the high flexibility of MWT-S-270 as well as the active site needs to be considered in future structure based drug design approaches.

Supplementary Materials: The following are available online at https://www.mdpi.com/article/10 $.3390 /$ ijms22115651/s1.

Author Contributions: M.L., D.S., D.R., S.S., H.-U.D. designed research; M.L., C.F., M.K., M.W. performed research; M.L., C.F., D.S., C.J., M.K., C.P. analyzed data; M.L., C.F., D.R., C.J., M.K., C.P., S.S. wrote the manuscript. All authors have read and agreed to the published version of the manuscript.

Funding: This research received no external funding.

Institutional Review Board Statement: Not applicable.

Informed Consent Statement: Not applicable.

Data Availability Statement: Structure coordinates und reflection data of Meprin $\beta^{62-595}(\mathrm{M} \beta \Delta \mathrm{C})$ homodimer (Meprin B) crystal structure in complex with MWT-S-270 has been deposited at PDB (protein data bank; https:/ / www.wwpdb.org/ (accessed on 5 May 2021)) under accession code 7AQ1. The inhibitor MWT-S-270 has been deposited as chemical compound as RUE (CC ID).

Acknowledgments: We thank Milton T. Stubbs for critical comments on the experiments and the manuscript. Further the technical assistance of Mercedes Scharfe is gratefully acknowledged. We thank the teams of beamline MX14.2, BESSY II storage ring (Berlin, Germany) and beamline i03, Diamond Light Source (Oxfordshire, UK) for beamtime allocation and assistance with crystallographic data collection and the team of the DLS-CCP4 Data Collection and Structure Solution Workshop 2017 for help and guidance during structure determination.

Conflicts of Interest: The authors declare no conflict of interest. C.J. is an employee and S.S. a consultant of Vivoryon Therapeutics N. V.

\section{References}

1. Sterchi, E.E.; Green, J.R.; Lentze, M.J. Non-pancreatic hydrolysis of N-benzoyl-1-tyrosyl-p-aminobenzoic acid (PABA-peptide) in the human small intestine. Clin. Sci. 1982, 62, 557-560. [CrossRef] [PubMed]

2. Beynon, R.J.; Shannon, J.D.; Bond, J.S. Purification and characterization of a metallo-endoproteinase from mouse kidney. Biochem. J. 1981, 199, 591-598. [CrossRef]

3. Sterchi, E.E.; Stöcker, W.; Bond, J.S. Meprins, membrane-bound and secreted astacin metalloproteinases. Mol. Asp. Med. 2008, 29, 309-328. [CrossRef]

4. Broder, C.; Arnold, P.; Vadon-Le Goff, S.; Konerding, M.A.; Bahr, K.; Müller, S.; Overall, C.M.; Bond, J.S.; Koudelka, T.; Tholey, A.; et al. Metalloproteases meprin $\alpha$ and meprin $\beta$ are $C$ - and N-procollagen proteinases important for collagen assembly and tensile strength. Proc. Natl. Acad. Sci. USA 2013, 110, 14219-14224. [CrossRef] 
5. Prox, J.; Arnold, P.; Becker-Pauly, C. Meprin $\alpha$ and meprin $\beta$ : Procollagen proteinases in health and disease. Matrix Biol. 2015, 44-46, 7-13. [CrossRef]

6. Arnold, P.; Otte, A.; Becker-Pauly, C. Meprin metalloproteases: Molecular regulation and function in inflam-mation and fibrosis. Biochim. Biophys. Acta Mol. Cell Res. 2017, 1864, 2096-2104. [CrossRef] [PubMed]

7. Broder, C.; Becker-Pauly, C. The metalloproteases meprin $\alpha$ and meprin $\beta$ : Unique enzymes in inflammation, neurodegeneration, cancer and fibrosis. Biochem. J. 2013, 450, 253-264. [CrossRef] [PubMed]

8. Butler, P.E.; Bond, J.S. A latent proteinase in mouse kidney membranes. Characterization and relationship to meprin. J. Biol. Chem. 1988, 263, 13419-13426. [CrossRef]

9. Gorbea, C.M.; Flannery, A.V.; Bond, J.S. Homo- and heterotetrameric forms of the membrane-bound metal-loendopeptidases meprin A and B. Arch. Biochem. Biophys. 1991, 290, 549-553. [CrossRef]

10. Bertenshaw, G.P.; Norcum, M.T.; Bond, J.S. Structure of homo- and hetero-oligomeric meprin metalloproteases. Dimers, tetramers, and high molecular mass multimers. J. Biol. Chem. 2003, 278, 2522-2532. [CrossRef]

11. Peters, F.; Scharfenberg, F.; Colmorgen, C.; Armbrust, F.; Wichert, R.; Arnold, P.; Potempa, B.; Potempa, J.; Pie-trzik, C.U.; Häsler, R.; et al. Tethering soluble meprin $\alpha$ in an enzyme complex to the cell surface affects IBD-associated genes. FASEB J. 2019, 33, 7490-7504. [CrossRef]

12. Jiang, W.; Gorbea, C.M.; Flannery, A.V.; Beynon, R.J.; Grant, G.A.; Bond, J.S. The alpha subunit of meprin A. Molecular cloning and sequencing, differential expression in inbred mouse strains, and evidence for divergent evolution of the alpha and beta subunits. J. Biol. Chem. 1992, 267, 9185-9193. [CrossRef]

13. Beckmann, G.; Bork, P. An adhesive domain detected in functionally diverse receptors. Trends Biochem. Sci. 1993, 18, 40-41. [CrossRef]

14. Aricescu, A.R.; Hon, W.-C.; Siebold, C.; Lu, W.; van der Merwe, P.A.; Jones, E.Y. Molecular analysis of receptor protein tyrosine phosphatase mu-mediated cell adhesion. EMBO J. 2006, 25, 701-712. [CrossRef] [PubMed]

15. Uren, A.G.; Vaux, D.L. TRAF protiens and meprins share a conserved domain. Trends Biochem. Sci. 1996, 21, 244-245. [CrossRef]

16. Laitaoja, M.; Valjakka, J.; Jänis, J. Zinc coordination spheres in protein structures. Inorg. Chem. 2013, 52, 10983-10991. [CrossRef] [PubMed]

17. Marchand, P.; Tang, J.; Johnson, G.D.; Bond, J.S. COOH-terminal proteolytic processing of secreted and mem-brane forms of the alpha subunit of the metalloprotease meprin A. Requirement of the I domain for processing in the endoplasmic reticulum. J. Biol. Chem. 1995, 270, 5449-5456. [CrossRef]

18. Hahn, D.; Lottaz, D.; Sterchi, E.E. C-cytosolic and transmembrane domains of the N-benzoyl-L-tyrosyl-p-aminobenzoic acid hydrolase alpha subunit (human meprin alpha) are essential for its retention in the endoplasmic reticulum and C-terminal processing. Eur. J. Biochem. 1997, 247, 933-941. [CrossRef] [PubMed]

19. Bode, W.; Gomis-Rüth, F.X.; Huber, R.; Zwilling, R.; Stöcker, W. Structure of astacin and implications for acti-vation of astacins and zinc-ligation of collagenases. Nature 1992, 358, 164-167. [CrossRef]

20. Gomis-Rüth, F.X.; Stöcker, W.; Huber, R.; Zwilling, R.; Bode, W. Refined 1.8 A X-ray crystal structure of astacin, a zincendopeptidase from the crayfish Astacus astacus L. Structure determination, refinement, molecular structure and comparison with thermolysin. J. Mol. Biol. 1993, 229, 945-968. [CrossRef]

21. Arolas, J.L.; Broder, C.; Jefferson, T.; Guevara, T.; Sterchi, E.E.; Bode, W.; Stocker, W.; Becker-Pauly, C.; Go-mis-Ruth, F.X. Structural basis for the sheddase function of human meprin metalloproteinase at the plasma membrane. Proc. Natl. Acad. Sci. USA 2012, 109, 16131-16136. [CrossRef]

22. Bode, W.; Gomis-Rüth, F.-X.; Stöckler, W. Astacins, serralysins, snake venom and matrix metalloproteinases exhibit identical zinc-binding environments (HEXXHXXGXXH and Met-turn) and topologies and should be grouped into a common family, the 'metzincins'. FEBS Lett. 1993, 331, 134-140. [CrossRef]

23. Gomis-Rüth, F.X.; Trillo-Muyo, S.; Stöcker, W. Functional and structural insights into astacin metallopeptidases. Biol. Chem. 2012, 393, 1027-1041. [CrossRef] [PubMed]

24. Jiang, W.; Bond, J.S. Families of metalloendopeptidases and their relationships. FEBS Lett. 1992, 312, 110-114. [CrossRef]

25. Doll, B.A.; Villa, J.P.; Ishmael, F.T.; Bond, J.S. Zinc ligands in an astacin family metalloprotease meprin A. Biol. Chem. 2002, 383, 1167-1173. [CrossRef]

26. Stöcker, W.; Ng, M.; Auld, D.S. Fluorescent oligopeptide substrates for kinetic characterization of the specifici-ty of Astacus protease. Biochemistry 1990, 29, 10418-10425. [CrossRef]

27. Grams, F.; Dive, V.; Yiotakis, A.; Yiallouros, I.; Vassiliou, S.; Zwilling, R.; Bode, W.; Stöcker, W. Structure of astacin with a transition-state analogue inhibitor. Nat. Struct. Biol. 1996, 3, 671-675. [CrossRef] [PubMed]

28. Bertenshaw, G.P.; Turk, B.E.; Hubbard, S.J.; Matters, G.L.; Bylander, J.E.; Crisman, J.M.; Cantley, L.C.; Bond, J.S. Marked differences between metalloproteases meprin A and B in substrate and peptide bond specificity. J. Biol. Chem. 2001, 276, 13248-13255. [CrossRef] [PubMed]

29. Villa, J.P.; Bertenshaw, G.P.; Bond, J.S. Critical amino acids in the active site of meprin metalloproteinases for substrate and peptide bond specificity. J. Biol. Chem. 2003, 278, 42545-42550. [CrossRef]

30. Kruse, M.-N.; Becker, C.; Lottaz, D.; Köhler, D.; Yiallouros, I.; Krell, H.-W.; Sterchi, E.E.; Stöcker, W. Human meprin alpha and beta homo-oligomers: Cleavage of basement membrane proteins and sensitivity to metallo-protease inhibitors. Biochem. J. 2004, 378, 383-389. [CrossRef] 
31. Ramsbeck, D.; Hamann, A.; Richter, G.; Schlenzig, D.; Geissler, S.; Nykiel, V.; Cynis, H.; Schilling, S.; Buchholz, M. Structureguided design, synthesis, and characterization of next-generation meprin $\beta$ inhibitors. J. Med. Chem. 2018, 61, 4578-4592. [CrossRef] [PubMed]

32. Ramsbeck, D.; Hamann, A.; Schlenzig, D.; Schilling, S.; Buchholz, M. First insight into structure-activity rela-tionships of selective meprin $\beta$ inhibitors. Bioorg. Med. Chem. Lett. 2017, 27, 2428-2431. [CrossRef] [PubMed]

33. Tan, K.; Jäger, C.; Schlenzig, D.; Schilling, S.; Buchholz, M.; Ramsbeck, D. Tertiary-amine-based inhibitors of the astacin protease meprin $\alpha$. ChemMedChem 2018, 13, 1619-1624. [CrossRef]

34. Schlenzig, D.; Wermann, M.; Ramsbeck, D.; Moenke-Wedler, T.; Schilling, S. Expression, purification and initial characterization of human meprin $\beta$ from Pichia pastoris. Protein Expr. Purif. 2015, 116, 75-81. [CrossRef]

35. Yiallouros, I.; Kappelhoff, R.; Schilling, O.; Wegmann, F.; Helms, M.W.; Auge, A.; Brachtendorf, G.; Berkhoff, E.G.; Beermann, B.; Hinz, H.-J.; et al. Activation mechanism of pro-astacin: Role of the pro-peptide, tryptic and autoproteolytic cleavage and importance of precise amino-terminal processing. J. Mol. Biol. 2002, 324, 237-246. [CrossRef]

36. Diederichs, K.; Karplus, P.A. Improved R-factors for diffraction data analysis in macromolecular crystallog-raphy. Nat. Struct. Biol. 1997, 4, 269-275. [CrossRef]

37. Harding, M.M. Small revisions to predicted distances around metal sites in proteins. Acta Crystallogr. D Biol. Crystallogr. 2006, 62, 678-682. [CrossRef] [PubMed]

38. Gomis-Rüth, F.X.; Botelho, T.O.; Bode, W. A standard orientation for metallopeptidases. Biochim. Biophys. Acta 2012, 1824, 157-163. [CrossRef]

39. Kabsch, W.; Sander, C. Dictionary of protein secondary structure: Pattern recognition of hydrogen-bonded and geometrical features. Biopolymers 1983, 22, 2577-2637. [CrossRef]

40. Kumar, S.; Nussinov, R. Close-range electrostatic interactions in proteins. ChemBioChem 2002, 3, 604. [CrossRef]

41. Becker-Pauly, C.; Barre, O.; Schilling, O.; auf dem Keller, U.; Ohler, A.; Broder, C.; Schutte, A.; Kappelhoff, R.; Stöcker, W.; Overall, C.M. Proteomic analyses reveal an acidic prime side specificity for the astacin metal-loprotease family reflected by physiological substrates. Mol. Cell. Proteom. 2011, 10, M111.009233. [CrossRef] [PubMed]

42. Schulz, G.E.; Schirmer, R.H. Principles of Protein Structure; Springer: New York, NY, USA, 1979 ; ISBN 9780387903347.

43. Marcus, Y.; Hefter, G. Ion pairing. Chem. Rev. 2006, 106, 4585-4621. [CrossRef] [PubMed]

44. Shiroishi, M.; Yokota, A.; Tsumoto, K.; Kondo, H.; Nishimiya, Y.; Horii, K.; Matsushima, M.; Ogasahara, K.; Yu-tani, K.; Kumagai, I. Structural evidence for entropic contribution of salt bridge formation to a protein anti-gen-antibody interaction: The case of hen lysozyme-HyHEL-10 Fv complex. J. Biol. Chem. 2001, 276, 23042-23050. [CrossRef] [PubMed]

45. Schulze, A.; Wermann, M.; Demuth, H.-U.; Yoshimoto, T.; Ramsbeck, D.; Schlenzig, D.; Schilling, S. Continuous assays for meprin alpha and beta using prolyl tripeptidyl aminopeptidase (PtP) from Porphyromonas gingivalis. Anal. Biochem. 2018, 559, 11-16. [CrossRef] [PubMed]

46. Kabsch, W. XDS. Acta Crystallogr. D Biol. Crystallogr. 2010, 66, 125-132. [CrossRef]

47. McCoy, A.J.; Grosse-Kunstleve, R.W.; Adams, P.D.; Winn, M.D.; Storoni, L.C.; Read, R.J. Phaser crystallographic software. J. Appl. Crystallogr. 2007, 40, 658-674. [CrossRef]

48. Adams, P.D.; Afonine, P.V.; Bunkóczi, G.; Chen, V.B.; Davis, I.W.; Echols, N.; Headd, J.J.; Hung, L.-W.; Kapral, G.J.; Grosse-Kunstleve, R.W.; et al. PHENIX: A comprehensive Python-based system for macromolecular structure solution. Acta Crystallogr. D Biol. Crystallogr. 2010, 66, 213-221. [CrossRef]

49. Winn, M.D.; Ballard, C.C.; Cowtan, K.D.; Dodson, E.J.; Emsley, P.; Evans, P.R.; Keegan, R.M.; Krissinel, E.B.; Leslie, A.G.W.; McCoy, A.; et al. Overview of the CCP4 suite and current developments. Acta Crystallogr. D Biol. Crystallogr. 2011, 67, $235-242$. [CrossRef]

50. Nettleship, J. Structural biology of glycoproteins. In Glycosylation; Petrescu, S., Ed.; InTech: Rijeka, Croatia, 2012; ISBN 978-953-510771-2.

51. Trimble, R.B.; Atkinson, P.H.; Tschopp, J.F.; Townsend, R.R.; Maley, F. Structure of oligosaccharides on Saccharomyces SUC2 invertase secreted by the methylotrophic yeast Pichia pastoris. J. Biol. Chem. 1991, 266, 22807-22817. [CrossRef]

52. Zheng, H.; Chordia, M.D.; Cooper, D.R.; Chruszcz, M.; Müller, P.; Sheldrick, G.M.; Minor, W. Validation of metal-binding sites in macromolecular structures with the CheckMyMetal web server. Nat. Protoc. 2014, 9, 156-170. [CrossRef]

53. Agirre, J.; Iglesias-Fernández, J.; Rovira, C.; Davies, G.J.; Wilson, K.S.; Cowtan, K.D. Privateer: Software for the conformational validation of carbohydrate structures. Nat. Struct. Mol. Biol. 2015, 22, 833-834. [CrossRef] [PubMed]

54. Krissinel, E. Stock-based detection of protein oligomeric states in jsPISA. Nucleic Acids Res. 2015, 43, W314-W319. [CrossRef] [PubMed]

55. Labute, P. Protonate3D: Assignment of ionization states and hydrogen coordinates to macromolecular structures. Proteins 2009, 75, 187-205. [CrossRef] [PubMed]

56. Maier, J.A.; Martinez, C.; Kasavajhala, K.; Wickstrom, L.; Hauser, K.E.; Simmerling, C. ff14SB: Improving the accuracy of protein side chain and backbone parameters from ff99SB. J. Chem. Theory Comput. 2015, 11, 3696-3713. [CrossRef]

57. Horn, H.W.; Swope, W.C.; Pitera, J.W.; Madura, J.D.; Dick, T.J.; Hura, G.L.; Head-Gordon, T. Development of an improved four-site water model for biomolecular simulations: TIP4P-Ew. J. Chem. Phys. 2004, 120, 9665-9678. [CrossRef]

58. Li, P.; Roberts, B.P.; Chakravorty, D.K.; Merz, K.M. Rational design of particle mesh Ewald compatible Lennard-Jones parameters for +2 metal cations in explicit solvent. J. Chem. Theory Comput. 2013, 9, 2733-2748. [CrossRef] [PubMed] 
59. Li, P.; Merz, K.M. Taking into account the ion-induced dipole interaction in the nonbonded model of ions. J. Chem. Theory Comput. 2014, 10, 289-297. [CrossRef]

60. Panteva, M.T.; Giambaşu, G.M.; York, D.M. Force field for $\mathrm{Mg}(2+), \mathrm{Mn}(2+), \mathrm{Zn}(2+)$, and $\mathrm{Cd}(2+)$ ions that have balanced interactions with nucleic acids. J. Phys. Chem. B 2015, 119, 15460-15470. [CrossRef]

61. Roe, D.R.; Cheatham, T.E. PTRAJ and CPPTRAJ: Software for processing and analysis of molecular dynamics trajectory data. J. Chem. Theory Comput. 2013, 9, 3084-3095. [CrossRef]

62. Humphrey, W.; Dalke, A.; Schulten, K. VMD: Visual molecular dynamics. J. Mol. Graph. 1996, 14, 33-38. [CrossRef]

63. Stone, J. An Efficient Library for Parallel Ray Tracing and Animation. Master's Thesis, University of Missouri-Rolla, Rolla, MO, USA, 1998

64. Frishman, D.; Argos, P. Knowledge-based protein secondary structure assignment. Proteins 1995, 23, 566-579. [CrossRef] [PubMed]

65. RStudio Team. RStudio: Integrated Development for R; RStudio, Inc.: Boston, MA, USA, 2016.

66. R Core Team. R. A Language and Environment for Statistical Computing; R Foundation for Statistical Computing: Vienna, Austria, 2019.

67. Grant, B.J.; Rodrigues, A.P.C.; ElSawy, K.M.; McCammon, J.A.; Caves, L.S.D. Bio3d: An R package for the com-parative analysis of protein structures. Bioinformatics 2006, 22, 2695-2696. [CrossRef] [PubMed]

68. Skjærven, L.; Yao, X.-Q.; Scarabelli, G.; Grant, B.J. Integrating protein structural dynamics and evolutionary analysis with Bio3D. BMC Bioinform. 2014, 15, 399. [CrossRef]

69. Skjærven, L.; Jariwala, S.; Yao, X.-Q.; Grant, B.J. Online interactive analysis of protein structure ensembles with Bio3D-web. Bioinformatics 2016, 32, 3510-3512. [CrossRef]

70. Plotly Technologies Inc. Collaborative Data Science; Plotly Technologies Inc.: Montréal, QC, Canada, 2015.

71. Tan, K.; Jäger, C.; Körschgen, H.; Geissler, S.; Schlenzig, D.; Buchholz, M.; Stöcker, W.; Ramsbeck, D. Heteroaromatic inhibitors of the astacin proteinases meprin $\alpha$, meprin $\beta$ and ovastacin discovered by a scaffold-hopping approach. ChemMedChem 2020. [CrossRef] 